\title{
Assessment of the importance of the current-wave coupling in the shelf ocean forecasts
}

\author{
G. Jordà ${ }^{1,2}$, R. Bolaños ${ }^{2}$, M. Espino ${ }^{2}$, and A. Sánchez-Arcilla ${ }^{2}$ \\ ${ }^{1}$ Institut Mediterrani d'Estudis Avançats (IMEDEA), c./Miquel Marqués 21, 07190 Esporles, Illes Balears, Spain \\ ${ }^{2}$ Laboratori d'Enginyeria Martima (LIM-UPC), c./Jordi Girona 1-3, mòdul D1 Campus Nord UPC, 08034 Barcelona, Spain
}

Received: 27 July 2006 - Published in Ocean Sci. Discuss.: 25 October 2006

Revised: 14 February 2007 - Accepted: 30 June 2007 - Published: 11 July 2007

\begin{abstract}
The effects of wave-current interactions on shelf ocean forecasts is investigated in the framework of the MFSTEP (Mediterranean Forecasting System Project Towards Enviromental Predictions) project. A one way sequential coupling approach is adopted to link the wave model (WAM) to the circulation model (SYMPHONIE). The coupling of waves and currents has been done considering four main processes: wave refraction due to currents, surface wind drag and bottom drag modifications due to waves, and the wave induced mass flux. The coupled modelling system is implemented in the southern Catalan shelf (NW Mediterranean), a region with characteristics similar to most of the Mediterranean shelves. The sensitivity experiments are run in a typical operational configuration. The wave refraction by currents seems to be not very relevant in a microtidal context such as the western Mediterranean. The main effect of waves on current forecasts is through the modification of the wind drag. The Stokes drift also plays a significant role due to its spatial and temporal characteristics. Finally, the enhanced bottom friction is just noticeable in the inner shelf.
\end{abstract}

\section{Introduction}

Progressively, operational oceanography is gaining in importance for coastal societies and the increasing socio-economic activities which depend on the sea. The improvements in observing and modelling systems have allowed an optimistic view about the future of operational products. This, along with the increasing demand from potential users (administrations, tourism industry, coastal managers, ...) have led the scientific community to join efforts in improving such operational systems.

Correspondence to: G. Jordà

(gabriel.jorda@uib.es)
Following this line, the Mediterranean Forecasting System project (MFS - http://www.bo.ingv.it/mfstep, Pinardi et al., 2003) was launched with the goal of providing reliable forecasts of the ocean state at different scales (basin, subbasin and shelf regions). The followed strategy has been the classical approach where a hierarchy of models at different resolutions are nested. At the top of the chain there is the large scale (basin) model which assimilates real data in order not to diverge from reality. This model provides the initial and open boundary conditions to the regional models (subbasin) which cover a smaller domain with higher resolution $(\sim 3 \mathrm{~km})$. In the final step, these models also provide information to local models (shelf regions) able to resolve spatial scales of about $1 \mathrm{~km}$ (see Fig. 1).

This present situation of the MFS will, in the near future, reach higher resolutions $(\sim 100-200 \mathrm{~m})$ in coastal domains (e.g. MOON project, http://www.bo.ingv.it/moon). However, if such scales are reached, a detailed review of modelling components should be performed. In particular, the coastal ocean is influenced by wind-waves and a complete picture of the coastal sea state should include them and the downward cascading in turbulence associated to the various boundary layers.

Wave-current coupling is becoming a classical issue in the literature. In the last years, the scientific community is paying more attention to the several aspects of wave-current interaction. Mastenbroek et al. (1993) showed how a wavedependent bottom drag coefficient improved the results of a 2-D storm surge model in the North Sea. Davies and Lawrence (1994) included the enhancement of the bottom friction due to wave-current coupling in a 3-D model of the Irish Sea. They showed that significant changes of tidal current profiles in shallow areas were produced by the enhanced frictional effects associated with wind-driven flow and wind wave turbulence. Baumert et al. (2000), using a coupled wave-tidal-circulation model, showed the relevance of wave action over the stress at the sea bed and thereby erosion and

Published by Copernicus Publications on behalf of the European Geosciences Union. 


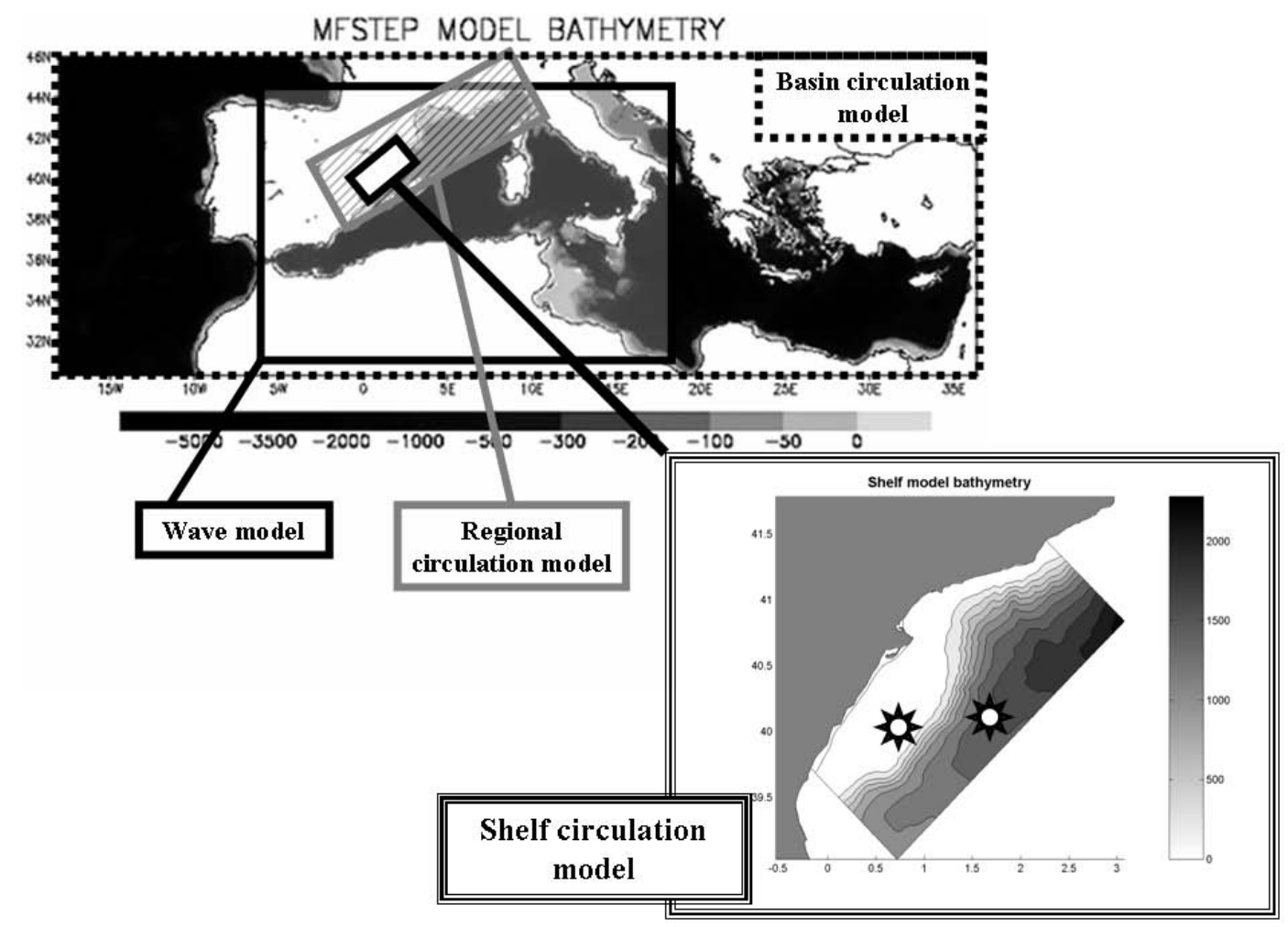

Fig. 1. Nested models domain. Shelf model domain and bathymetry. The stars mark the points where the time series are obtained.

suspension of particulated matter. Weber (2003) investigated the mean transport induced by waves in the surface layers and its applications to ocean circulation models. In the same line, Perrie et al. (2003), just considering the Stokes drift and the wave breaking dissipation, have seen that in rapidly developing storms, the wave-modified currents can be of the order of $40 \%$ of the Ekman currents. Kantha and Clayson (2004) used a 1-D model to enlight the effects of waves in the surface mixed layer. They demonstrated how the wave breaking enhance the turbulent kinetic energy in surface but also that it has a low impact in the mixed layer formation. However, they also showed how the energy input to turbulence through the Langmuir cells is an effective mechanism to deepen the surface mixed layer. Other research dealing with wave induced turbulence are Ardhuin and Jenkins (2006), Melsom and Setra (2004) and Craig and Banner (1994) who have studied the vertical distribution of turbulence due to waves and its relation to the turbulence closure theory as the one by Mellor and Yamada (1982). Finally, recent efforts are being done to propose a unified formalism for waves and currents (Mellor, 2003, 2005; Rascle et al., 2006). This approach is probably the best option for considering the joint effect of waves and currents but its practical implementation is not yet available. In spite of all that work and as far as we know, the issue of wave-current coupling in 3-D operational forecasts has not been treated yet. On the other hand, most of the previous results have been obtained in macrotidal contexts, where tidal currents usually largely dominate the dynamics. However, in microtidal contexts, the relative importance of the Stokes drift, for instance, can be comparable to the termohaline circulation.

Until now, in most operational systems, the waves and the current forecasts have been done independently (Pinardi et al., 2003; Bolaños et al., 2004). The reasons have been practical (e.g. for efficient implementations) and because it can be considered that at first order, they are not highly dependent processes. Nevertheless, if the degree of accuracy is to be improved, it would be required to test how the coupling of these processes could affect the forecasts in those areas.

The goal of this work is to test how the coupling of waves and currents could affect the 3-D hydrodynamic forecasts in shelf and coastal regions in a microtidal context, and to see which elements should be included in the next phases of operational implementations in the Mediterranean Sea. Unfortunately there is no available data to accurately validate such model results (at least in our study area), so it seems logical to start to investigate this issue through sensitivity analysis. Because the aim is to focus on the operational issues, the modelling system configuration is the same configuration used in the operational forecasting in the Catalan shelf.

We have focused on the Western Mediterranean, a semienclosed microtidal sea with strong gradients in the wind and the bathymetry. The study site is the southern Catalan shelf-slope region in the NW Mediterranean (see Fig. 1). 
The dynamics of this microtidal region are dominated by a quasi-permanent slope current (the Northern current; Millot, 1999), with typical values of $30-40 \mathrm{~cm} / \mathrm{s}$ in surface. Several mesoscale features such as eddies or current meandering are also usually found (Font et al., 1995). The shelf dynamics are influenced by the slope current variability, the Ebro river outflow and the wind forcing. In the Ebro delta ( $40.4^{\circ}$ to $41^{\circ} \mathrm{N}$ and $0.3^{\circ}$ to $1.2^{\circ} \mathrm{E}$ ) (Fig. 1) the local topography, with the coastal mountain chain breached by the Ebro river valley exerts a significant control on wind climate. In general, four wind directions dominate in this area: NE, E, SW and NW. The NW condition produces local wind waves with short periods due to the fetch limitation (García et al., 1993). The maximum velocities have been recorded for eastern winds in agreement with storm conditions associated to cyclonic activity over the western Mediterranean. The mean wave climate near the Ebro delta coast shows that the yearly mean significant wave height $(\mathrm{Hs})$ is about $0.8 \mathrm{~m}$. The maximum recorded Hs was $6 \mathrm{~m}$, corresponding to maximum wave heights of $10 \mathrm{~m}$. The maximum recorded wave peak period was $14.3 \mathrm{~s}$, with a yearly mean of $5 \mathrm{~s}$.

These features are quite common in most of the Mediterranean shelf regions, so the results presented in this paper should be applicable to other regions with similar characteristics.

The paper is structured as follows. In Sect. 2, the wave model and the circulation models are briefly presented. The wave-current coupling formulation adopted in our system is explained in Sect. 3 and the sensitivity experiments with the different coupling factors are presented in Sect. 4. The results and their implications for the operational systems are in Sect. 5, and the summary and conclusions are presented in Sect. 6.

\section{Wave and current modelling}

\subsection{The wave model}

The WAM model (Komen et al., 1994; Monbaliu et al., 2000) is a third generation wind-wave model which solves the spectral evolution (2-D spectrum) of sea state considering wind input, dissipation and nonlinear wave-wave energy transfer.

Moreover, the shallow version of WAM is used in which bottom effects are considered through dissipation and refraction. In our case, the model is implemented in a grid covering the Mediterranean at latitudes from $34^{\circ} \mathrm{N}$ to $45^{\circ} \mathrm{N}$ and longitudes from $-5^{\circ} \mathrm{W}$ to $18^{\circ} \mathrm{E}$ and (see Fig. 1) with a resolution of $0.1^{\circ}(10 \mathrm{~km}$ mesh size approximately). The WAM runs with 30 frequencies and 24 directions with the lowest frequency at $0.041 \mathrm{~s}^{-1}$. The propagation and source time steps are set to $600 \mathrm{~s}$.

For the experiments presented in this paper, the wave model has been forced with the wind fields from the ALADIN meteorological model (Radnóti et al., 1995) with a spatial resolution of $10 \mathrm{~km}$ and a temporal resolution of $1 \mathrm{~h}$. The description of the model configuration used in the MFSTEP operational system can be found in Brozková et al. (2006).

With this model configuration, Bolaños et al. $(2007,2004)$ have performed a validation of the WAM for the NW Mediterranean and in particular the Ebro delta region. These authors have shown a general significant wave heigth negative bias and a RMSE of more than $0.5 \mathrm{~m}$. The sources of error were also discussed in such references. For the application presented here the general underestimation of wave energy may affect the magnitude of some of the coupling terms (see Sect. 4) but not the general pattern, which is the main outline of this paper.

\subsection{The circulation model}

The ocean circulation model used in this work is the SYMPHONIE model (Estournel et al., 2003). It is a finite difference, hydrostatic, 3-D primitive equation model which has been successfully used in several coastal areas such as the Gulf of Lions (Auclair et al., 2001), the Thermaikos bay (Estournel et al., 2005), and the Catalan shelf (Jordà, 2005). This model has been implemented in the southern part of the Catalan shelf-slope area (see Fig. 1) with a resolution of $1 \mathrm{~km}$. An important feature of this model is that it uses hybrid $(\sigma-\mathrm{z})$ coordinates in the vertical. Schematically it can be said that in shallow areas the levels are a function of the bathymetry but in the places where the slope of the levels reaches the hydrostatic inconsistency (Haney, 1991) a new z-level is introduced. As a result the number of levels increases in the open sea. This approach allows a good resolution of the surface mixed layer, provides a good representation of the bottom processes over the shelf and drastically reduces the truncation error (Jordà et al., 2004). In our implementation we have used 20 levels in the shallower areas and about 41 in the open sea. The typical vertical resolution near the surface is $30 \mathrm{~cm}$ over the shelf and $80 \mathrm{~cm}$ in the open sea.

The atmospheric forcing of the model is done through a one-way coupling of the atmospheric variables provided by a meteorological model with the sea surface temperature from the oceanic model. The chosen method is based on an iterative formulation (Geernaert, 1990) and it has been successfully tested in real cases (Dufau-Juilland et al., 2004). The meteorological model used is the same ALADIN model that forces the wave model with a spatial resolution of $10 \mathrm{~km}$ and a temporal resolution of $1 \mathrm{~h}$.

For the bottom boundary condition, SYMPHONIE uses a typical quadratic law for the bottom stress. In the usual configuration, the bottom drag coefficient is set to a constant value of $1.510^{-3}$.

In the MFSTEP configuration, our shelf model is nested into a regional model with coarser resolution $(3 \mathrm{~km})$ which provides the initial fields and the open boundary conditions updated every hour. 
WAVE MODEL

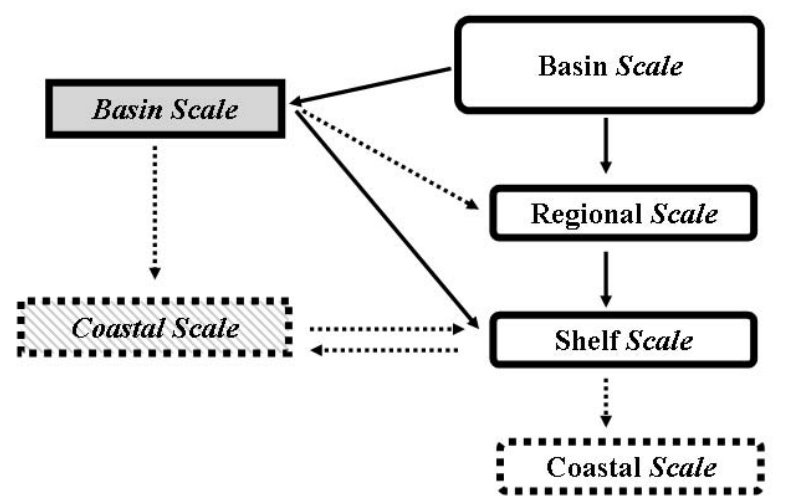

Fig. 2. Sketch of the current-wave coupling. The solid lines are the links implemented in our system. The dotted lines are links that are not yet implemented.

\section{Wave-current coupling}

The wave current coupling has been done following the work of previous authors (Davies and Lawrence, 1994; Perrie et al., 2003; Moon, 2005) but considering the practical issues inherent to an operational system. In the case of a system such as the MFS, it may be quite complex to run a coupled wave-current model at very high resolution and taking the small scale physics into account, at least at this phase of development and with the available resources. In our case, the usual configuration is that different teams run the different models (waves and currents) at different resolutions (from basin to local scales). In consequence, we opted to follow a simplifying strategy which takes into account the practical operational constraints.

Our approach is to do a sequential one-way coupling which avoids to run simultaneously the different models (see Fig. 2). In a first step the results of the general (coarser resolution) circulation model are introduced into the wave model as well as being used to give initial and open boundary conditions to the regional circulation model. In the second step this regional model provides the information to be nested inside in the coastal model which also uses the wave model results to consider wave effects. Eventually, this procedure could be extended to higher resolution models (both wave and circulation) until reaching the desired coastal scale.

It is clear that the number of links between models could be increased (see dotted lines in Fig. 2). Nevertheless this exceeds the goals of this exploratory work, where we are just looking for the impact of the coupling in the shelf region forecasts.

The coupling of waves and currents has been done considering four main processes: wave refraction due to currents, surface wind drag and bottom drag modifications due to waves and the wave induced mass flux (see below for a more complete description).
Other coupling processes used by other authors but that were not included here are the wave breaking and the radiation stress. Wave breaking outside the depth-controlled zone is certainly an important process in the wave-current coupling via mass and momentum transfers. However this mechanism is far from straightforward, particularly when considering the enhanced fluxes of mass and momentum associated to white capping. Therefore in this first estimate of wave-current coupling it has not been further considered. The gradients of the radiation stress were not included either. The reason is that, in the state-of-the-art formulations, the effect of stratification (as it is the case for a microtidal sea as the Mediterranean) is not considered when computing those terms. Thus, we have no idea about the error assumed when computing them. In addition to that, it is assumed that the gradients of the radiation stress when there is no wave breaking, just produce a variation of the mean sea level. Except for very coastal areas, those variations are not relevant (SánchezArcilla and Lemos, 1990). On the other hand, the inclusion of wind induced wave breaking is a complex process that exceeds the goal of this work.

Another important issue is which parametrizations were chosen to describe the selected coupling processes. This implies a subjective choice among all possibilities, so the choices could be further discussed. Nevertheless, it should be kept in mind that the idea of this paper is to evaluate the sensitivity to the various current-wave coupling processes (as far as there is no available data).

\subsection{DH wave refraction by currents}

The effect of depth-mean currents on the waves has been taken into account by considering linear wave refraction induced by the underlying ocean circulation. In order to estimate the expected importance of this process, we can perform a simple consideration. The linear wave refraction $(2 \mathrm{DH})$ is a function of the ratio between the mean current $(\mathrm{u})$ and the phase celerity of waves (c). Typical values for this phase celerity are about $3-10 \mathrm{~m} / \mathrm{s}$ while the surface currents in the Mediterranean range between $0.2-0.6 \mathrm{~m} / \mathrm{s}$. Thus, the ratio $\mathrm{u} / \mathrm{c}$ is usually about 0.1 which indicates a small refraction. However, for some severe storm conditions the current velocities near the surface can be greater than $1 \mathrm{~m} / \mathrm{s}$ which can lead to a significant wave refraction.

This wave refraction process is explicitly introduced in the balance of wave action through the energy propagation in geographical and spectral space. The rate of change of wave direction $(\theta)$ by taking the currents into account can be written as (Komen et al., 1994):

$$
\begin{aligned}
\dot{\theta}= & \frac{1}{R}\left(\sin \theta\left[\cos \theta \frac{\partial}{\partial \phi} U_{\phi}+\sin \theta \frac{\partial}{\partial \phi} U_{\lambda}\right]\right. \\
& \left.-\frac{\cos \theta}{\cos \phi}\left[\cos \theta \frac{\partial}{\partial \lambda} U_{\phi}+\sin \theta \frac{\partial}{\partial \lambda} U_{\lambda}\right]\right)
\end{aligned}
$$


where $R$ is the earth radius and $U_{\phi}$ and $U_{\lambda}$ are the components of the current velocity in latitudinal $(\phi)$ and longitudinal $(\lambda)$ directions.

\subsection{Wind drag modified by waves}

The parameterization of the wind stress (drag) over the ocean is an essential issue in the ocean-atmosphere numerical analyses. After extensive research the parameterization of the ocean surface momentum flux in terms of a drag coefficient is still an uncertain process (Toba et al., 2001). The drag coefficient is commonly expressed in terms of the wind velocity (i.e. Wu, 1982), but the large scatter (Vickers and Mahrt, 1997; Toba et al., 2001) indicates that there are many more complex processes that are not taken into account. The drag over a solid surface is related to the surface properties (roughness) and therefore it is clear that, over the ocean, the surface gravity waves are part of the natural roughness and should be considered.

In our case we have adopted a formulation based on the quasi-linear theory of wind-wave generation developed by Janssen $(1989,1991)$. In this theory, the effective roughness length depends on the sea state through the wave induced stress estimated from wave spectra. The total surface stress $(\tau)$ is expressed by the sum of a wave-induced stress $\left(\tau_{w}\right)$ and a turbulent stress $\left(\tau_{t}\right)$. This last term is parametrized with a mixing length hypothesis while the first term $\left(\tau_{w}\right)$ is given by

$\tau_{w}=\rho \int_{0}^{\infty} \int_{0}^{2 \pi} \sigma S_{i n}\left(f_{r}, \theta\right) d f_{r} d \theta$

where $\rho$ is the water density, $\sigma$ is $2 \pi f_{r}$ and $S_{i n}$ is the input source term of the WAM model (Janssen, 1991).

The corresponding wind profile is then given by

$U(z)=\frac{u_{*}}{\kappa} \ln \left(\frac{z+z_{e}-z_{0}}{z_{e}}\right)$

where $u_{*}$ is the air friction velocity, $z_{0}$ is the roughness length in the absence of waves, and $z_{e}$ is the effective roughness. These are given by

$z_{e}=\frac{z_{0}}{\sqrt{1-\tau_{w} / \tau}} z_{0}=0.01 \frac{u_{*}}{g}$

\subsection{Wave induced mass flux}

In the usual description of the ocean, the momentum of the ocean waves is not taken into account, despite the fact that a considerable list of authors (Hasselmann, 1970; Weber, 1983; Jenkins, 1987; Xu and Bowen, 1994; McWilliams et al., 1997) have pointed out that, in a rotating ocean, the ocean waves excert a wave-induced stress on the Eulerian mean flow which results in a force equal to $f \boldsymbol{v}_{s}$, where $f$ is the Coriolis parameter, and $\boldsymbol{v}_{s}$ equals the Stokes drift.

In order to estimate the relevance of wave induced mass fluxes we can carry out a simple analysis of its magnitude.
The Stokes drift magnitude can be obtained as (Kantha and Clayson, 2004):

$\left|\boldsymbol{v}_{s}\right|=\left(u_{s}^{2}+v_{s}^{2}\right)^{1 / 2}=c(k a)^{2} \exp (2 k z)$

where $a$ is the wave amplitude, $c$ the wave speed and $k$ the wavenumber. In the Catalan Sea, typical values for these variables in a calm (storm) period are: $T=4(12) \mathrm{s}, a=0.5$ (4) $\mathrm{m}, k=0.1 \mathrm{~m}^{-1}$ and $c=3$ (12) $\mathrm{m} / \mathrm{s}$. With these values we obtain surface Stokes drift of $0.08(0.22) \mathrm{m} / \mathrm{s}$. On the other hand the mean circulation in the region has typical values of $20-30 \mathrm{~cm} / \mathrm{s}$ with episodic maximum values of $50-60 \mathrm{~cm} / \mathrm{s}$ associated to the slope current variability (Font et al., 1995 ). In consequence, the Stokes drift can be seen as a second order element of the system as it is usually an order of magnitude lower than the mean circulation. Nevertheless, under wave storm conditions, and specially where the main circulation is weak (i.e. over the mid shelf ) its significance can reach $40-50 \%$ of the total current field.

In our coupled model, the Stokes drift velocity components $\left(u_{s}, v_{s}\right)$ are computed from the wave spectrum $\Psi$ as (Moon, 2005):

$u_{s}(z)=\int_{0}^{\infty} \int_{0}^{2 \pi} c k^{2} \psi\left(f_{r}, \theta\right) \exp (2 k z) \cos \theta d f_{r} d \theta$
$v_{s}(z)=\int_{0}^{\infty} \int_{0}^{2 \pi} c k^{2} \psi\left(f_{r}, \theta\right) \exp (2 k z) \sin \theta d f_{r} d \theta$

where $c$ is the wave phase speed, $k$ is the wave number, $f_{r}$ is the frequency, $\theta$ the direction and $z$ is the depth.

Then, these velocities are introduced in the circulation model equations by updating the Coriolis term (McWilliams et al., 1997; Kantha and Clayson, 2004):

$+f U \rightarrow+f\left(U+u_{s}\right)$

$-f V \rightarrow-f\left(V+v_{s}\right)$

\subsection{Bottom drag coefficient}

The effect of enhanced bed turbulence when wind wave effects are present influences the flow field computed by the hydrodynamic model through an increase in the current bottom drag coefficient. In our case we have used the wavecurrent interaction model of Grant and Madsen (1979) as presented by Davies and Lawrence (1994). Here we just present the main points of the formulation, while a complete description can be found in those references.

The bottom current shear stress $\tau_{b}$ is defined as:

$\boldsymbol{\tau}_{b}=\frac{1}{2} f_{c} \rho\left|U_{b}\right| \boldsymbol{U}_{b}$

where $f_{c}$ is the current friction factor, $\rho$ is the water density and $U_{b}$ is the phase averaged velocity near the bottom.

The factor $f_{c}$ is determined from

$f_{c}=2\left[\frac{\kappa}{\ln \left(30 z_{r} / k_{b c}\right)}\right]^{2}$ 
Table 1. Summary of all simulations performed. See the text for a complete description of the simulations.

\begin{tabular}{|c|c|c|c|c|c|}
\hline \multicolumn{6}{|c|}{ Wave model (WAM) } \\
\hline Run & \multicolumn{5}{|c|}{ Currents included in the model } \\
\hline Reference & & \multicolumn{4}{|l|}{ None } \\
\hline Normal run & & \multicolumn{4}{|c|}{ MFSTEP general circulation model (OGCM) } \\
\hline Wind enhanced & & \multirow{2}{*}{\multicolumn{4}{|c|}{$\begin{array}{l}\text { MFSTEP - OGCM + synthetic wind induced currents } \\
\text { MFSTEP - OGCM + synthetic eddy field }\end{array}$}} \\
\hline Mesoscale enhar & ced & & & & \\
\hline \multicolumn{6}{|c|}{ Circulation model (symphonie) } \\
\hline Run & $\begin{array}{r}\text { Wa } \\
\text { win }\end{array}$ & $\begin{array}{l}\text { je modified } \\
\text { drag coeff. }\end{array}$ & $\begin{array}{l}\text { Stokes } \\
\text { drift }\end{array}$ & $\begin{array}{l}\text { Wave modified } \\
\text { bottom drag coeff. }\end{array}$ & Stratification \\
\hline Reference & & NO & NO & NO & Winter \\
\hline Wind drag & & YES & NO & NO & Winter \\
\hline Stokes drift & & NO & YES & NO & Winter \\
\hline Bottom drag & & NO & NO & YES & Winter \\
\hline Complete (3-term) & & YES & YES & YES & Winter \\
\hline Ref. Summer & & NO & NO & NO & Summer \\
\hline Comp. Summer & & YES & YES & YES & Summer \\
\hline
\end{tabular}

where $\kappa=0.4$ is the von Karman's constant and $z_{r}$ is the reference height at which the slip condition is applied. The apparent bottom roughness $k_{b c}$ felt by the current due to the presence of waves is given by

$k_{b c}=k_{b}\left[C_{1} \frac{U_{* c w} A_{b}}{U_{w} k_{b}}\right]^{\beta}$

Here $k_{b}$ is the bottom roughness, $U_{* c w}$ the friction velocity for waves and currents, $U_{w}$ the wave friction velocity, $C_{1}$ a dimensionless constant, $A_{b}$ a parameter related to the wave characteristics and $\beta$ a parameter related to the friction velocity for currents. The expresions to compute these parameters can be found in Davies and Lawrence (1994) and in Grant and Madsen (1979).

\section{Sensitivity experiments}

To evaluate the relative importance of each considered factor in the coupling, several sensitivity experiments have been performed. The aim is to test which processes have a greater impact on the obtained results, and, in consequence, need a careful consideration in the coupled operational systems.

The modelling conditions have been set to reproduce a typical operational configuration although no restart was done during the simulation. As it was mentioned previously, the wave model uses the current fields provided by the Mediterranean Ocean General Circulation Model (OGCM; $5 \mathrm{~km}$ resolution) every $6 \mathrm{~h}$ and the meteorological forcing provided by the ALADIN model ( $10 \mathrm{~km}$ resolution) every hour. With these forcings, the model generates the forecasts every hour with a spatial resolution of $10 \mathrm{~km}$. On the other hand the shelf circulation model takes the initial and open bondary conditions every hour from the MFSTEP regional model. The atmospheric data is taken from the ALADIN model and the wave data from the wave model described above.

The experiments have been run for two weeks, time enough to develop a wide range of processes by the different models. The simulation period chosen is January 2003 which coincides with the Scientific Validation Period of the MFSTEP project. It is also a period where the hydrodynamical conditions were interesting enough, featuring alterning storm-calm periods and being representative of the typical conditions of the NW Mediterranean in winter time.

The complete set of simulations is presented in Table 1. First of all we have performed a reference simulation where the wave and the shelf circulation models run without any coupling. This simulation was taken as the benchmark for the subsequent inter-comparison. Then, we first study the impact of currents on the wave forecasts by performing three different simulations with different current fields. We have explored the impact of currents in a typical situation (normal run), in a situation where the wind situation is specially severe (wind enhanced run) and the case where the mesoscale reproduced by the circulation model is specially high (mesoscale enhanced run). The complete description of these runs is included in Sect. 4.2). The next step was to study the impact of waves on the circulation model forecasts. We included the different coupling terms presented above, individually in a step by step manner. We have tested the impact of the enhanced wind drag (wind drag run), the 
wave-induced mass flux (Stokes drift run) and the waveenhanced bottom drag (bottom drag run). See Sects. 4.3-4.5 for a detailed description. Finally, we performed a last simulation including all the terms considered in this paper for current-wave coupling.

Another item that should be addressed is the impact of the seasonality. We need evaluate if the stratification, which partially unlinks the surface processes from the deep ocean, can modify the importance of the considered current-wave coupling. To do that, we repeat the reference simulation (Reference summer run) and that with the three-term coupling (Complete summer run) assuming a mean density profile typical from the summer. The data was obtained from the FANS project campaigns (Salat et al., 2002). Since we are looking for the effect of stratification, we have just changed the mean stratification while the winds, waves and open boundary conditions remained the same. This assumption is perfectly acceptable as far as the wind, waves and slope current situation modelled in the winter period could also be found in summer. The summer wind climate is different from the winter one but the N-NW storms are found also in summer. The same happens with the wave climate. Altought the modelled situation is not common in summer it is posible to find it. Finally, the open boundary conditions represent the permanent slope current which is basically identical trough the year. Thus, in order to isolate the effects of the stratification we decided to leave everything unchanged except the mean density profile.

\subsection{The reference run}

The atmospheric and wave conditions from 1 to 15 January 2003 are characterized by a variable sequence wich starts with a calm period from 1st to 4th. A blocking high pressure area between Iceland and the British Islands induces easterly winds over the western Mediterranean. At the end a cold front passes over the Iberian peninsula. Significant wave heights at the Catalan coast were lower than $1 \mathrm{~m}$ during these days. After this calm period, a storm event was recorded by the coastal wave buoys (XIOM network, http: //www.boiescat.org) from 5th to 8th. An Atlantic low deepens over the Gulf of Lions and travels fast up to the Adriatic sea which generates N-NW winds in the NW Mediterranean. The passage of a new front generates a mesoscale low in the Western Mediterranean. The significant wave height in the southern Catalan Shelf reached almost $3 \mathrm{~m}$ during the peak of the storm (see Fig. 3). After this, there came a calm period again until 10 January where moderate NW-winds start to blow remaining constant during four days.

The currents in the region are characterized by several mesoscale features which are present during all the simulation period. The Northern Current (Millot, 1999) is present over the slope with surface values reaching $40 \mathrm{~cm} / \mathrm{s}$. An anticyclonic eddy is placed over the narrow shelf near Barcelona, at the North of the numerical domain. It is fed by the slope
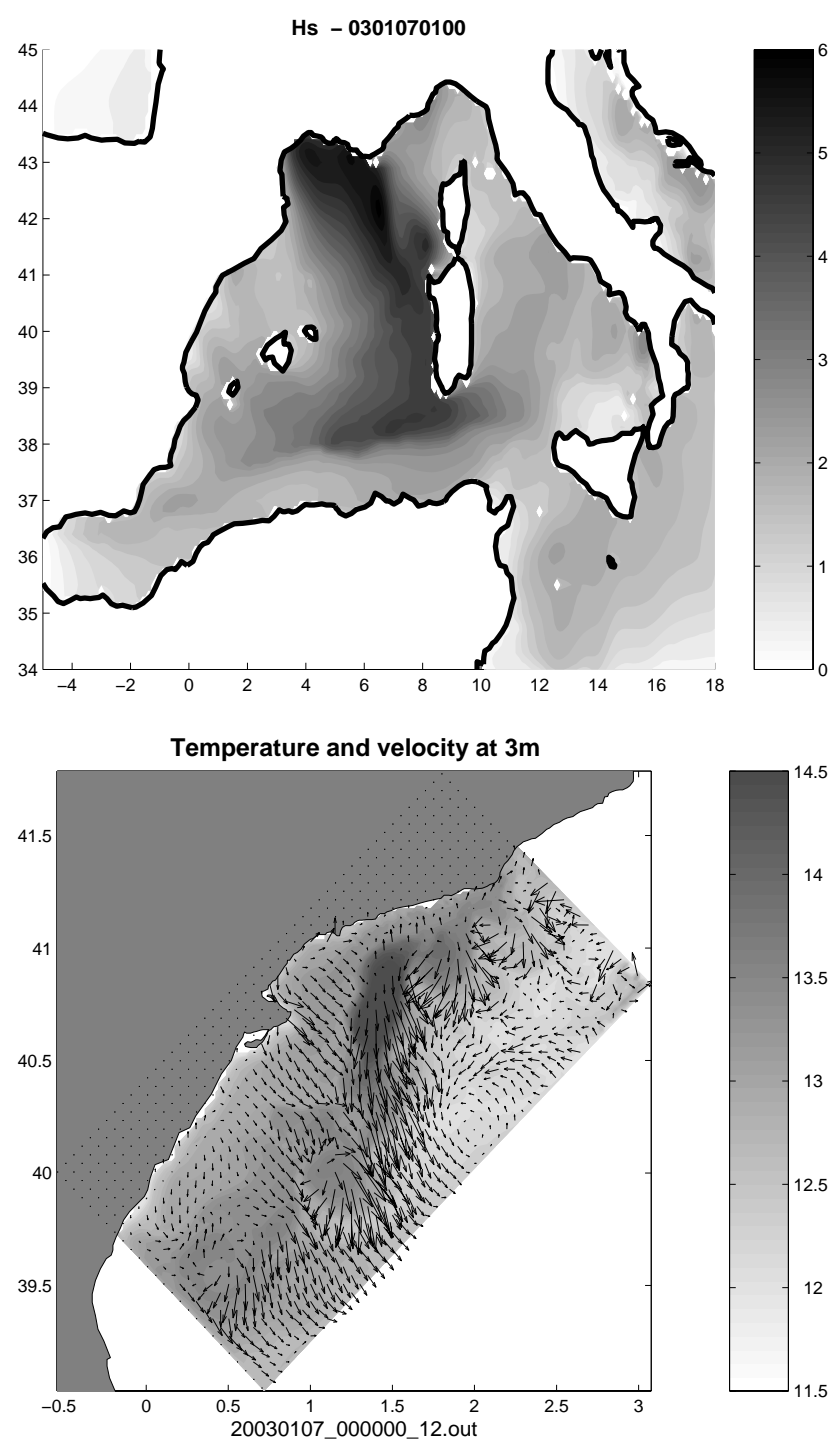

Fig. 3. Results of the reference run during the storm (7 January). (Top) Significative wave height. (Bottom) Surface temperature and currents in the shelf model domain.

current which also advects it southwestwards during the simulation period. The surface velocities associated to the eddy can reach $50 \mathrm{~cm} / \mathrm{s}$. In the southern relatively wider shelf, the situation is calmer, and no clear pattern is present. Overimposed on these structures, there is the wind induced current controlling the circulation in the surface mixed layer (see Fig. 3 bottom). This circulation is quite variable in space and time. The NW wind, channeled by the local orography, also induces the generation of an anticyclonic eddy over the shelf which remains stable after the storm. Finally, very energetic inertial oscillations are triggered by the wind variations over the whole domain. 

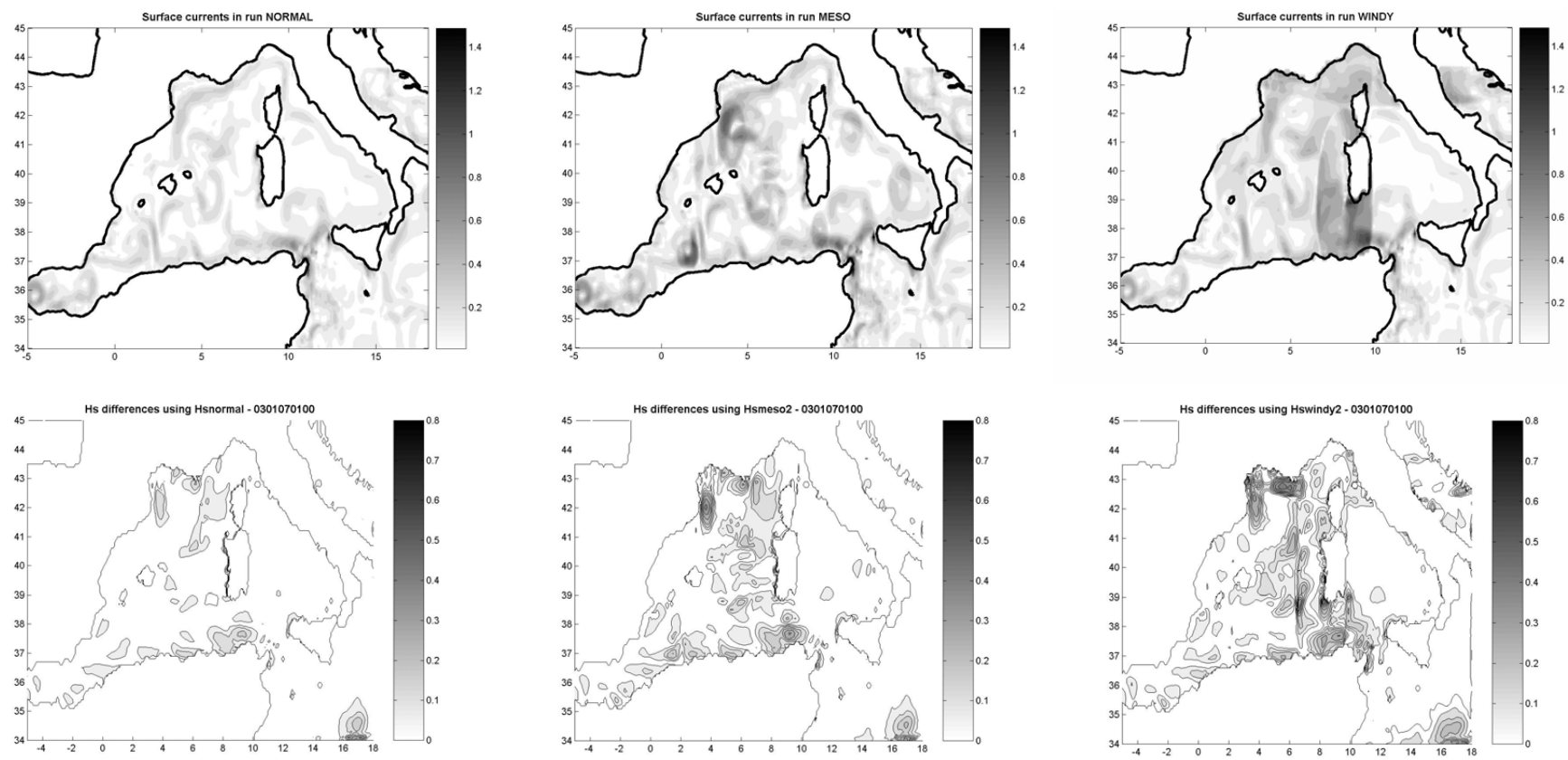

Fig. 4. Effects of refraction over the wave forecasts. In top there are the intensity of the modified circulation patterns for the OGCM surface velocity during the storm (max. values in the colorbar are $1.5 \mathrm{~m} / \mathrm{s}$ ). In the bottom row there are the significative height differences between the reference run and the runs with refraction (contour intervals $=5 \mathrm{~cm}$ ). On the left there is the MFSTEP field, in the middle the "mesoscale enhanced" run and on the right the "wind enhanced" run.

\subsection{Wave refraction}

The first approach has been to use the OGCM results as "they are", but introducing two consideration. First of all, the first velocity level in the OGCM is at $5 \mathrm{~m}$, so it is clear that the surface layer is not well represented. Second, it is possible that the mesoscale activity present in the circulation model is underestimated due to the coarse resolution of the forcings used. In order to estimate how these factors can influence wave refraction we have generated two complementary synthetic velocity fields.

In the first one (wind enhanced run), we have analytically computed the surface wind induced circulation associated to the winds provided by the meteorological model. To do that, we have used the classical Ekman formulation (Gill, 1982). Then we have added it to the OGCM original field. It is clear that doing this we are overestimating the surface circulation, but we consider it acceptable as a benchmark case for the sensitivity analysis. The second synthetic field (mesoscale enhanced run) has been generated by adding twelve eddytype structures into the OGCM velocity field. Their shape, location and orientation were randomly set and their radius ranged between 10 to $100 \mathrm{~km}$. It is again clear that there is no physical reason to add these structures, but the goal of assessing the effect of a more intense mesoscale activity on wave refraction justify it.

The different surface velocity fields (the original and the synthetic ones) and the resulting wave fields during the storm are presented in Fig. 4. It can be seen how the differences are, in average, quite small. Only when currents are very strong in the synthetic fields, the differences exceed $0.3 \mathrm{~m}$. It must be noted that this happens in the synthetic fields where the surface currents are likely to have been overestimated. The effects on refraction are localized where the currents are strong. In general, the patterns of difference coincide with the current velocity patterns, and no difference is found in calm regions. This is consistent with the employed $2 \mathrm{DH}$ linear refraction approach, which is a first approximation to the full refraction phenomenon. The refraction could then be viewed as a local effect present in the whole domain.

The differences between the behaviour over the shelf and over the open sea are summarized in Table 2. As it can be seen, the root mean square error (rmse) between the run with refraction and the reference run is never greater than $10 \mathrm{~cm}$ for both positions and for any of the experiments performed. However, the pointwise rmse may not be the best indicator of the relative importance of refraction in regions were the wave height is small. Thus, we computed the relative distance between the two runs over the original signal. This parameter is defined as:

$\alpha=\overline{\left(\frac{H^{\text {ref }}-H^{\text {refraction }}}{H^{\text {ref }}}\right)} * 100$

where $H$ is the wave height and $\alpha$ is expresed as a percentage. The values of the $\alpha$ parameter obtained over the shelf for the different runs (4\%-7.5\%, see Table 2$)$ are larger than 
Table 2. Rmse and relative distance $(\alpha)$ in different locations (see Fig. 1a for location of the points) for the different runs with refraction.

\begin{tabular}{lcccc}
\hline & \multicolumn{2}{c}{ RMSE $(\mathrm{m})$} & \multicolumn{2}{c}{$\alpha(\%)$} \\
\hline Experiment & $\begin{array}{c}\text { Catalan } \\
\text { shelf }\end{array}$ & $\begin{array}{c}\text { Open } \\
\text { sea }\end{array}$ & $\begin{array}{c}\text { Catalan } \\
\text { shelf }\end{array}$ & $\begin{array}{c}\text { Open } \\
\text { sea }\end{array}$ \\
\hline Normal & 0.035 & 0.045 & 4.62 & 1.66 \\
Wind enhanced & 0.035 & 0.071 & 5.66 & 4.83 \\
Mesoscale enhanced & 0.054 & 0.072 & 7.49 & 2.75 \\
\hline
\end{tabular}

for the open sea position $(1.5 \%-4.8 \%)$. This is because the wave heights in the Catalan shelf were lower $(\sim 3 \mathrm{~m})$ while the differences between the reference situation and the runs with refraction were quite similar in both positions. In any case, the differences, absolute and relative, are not very significative.

The low effect of currents on wave refraction justifies the sequential approach of this work where the waves and the currents are run independently. In conclusion, we should not expect a significant difference in the wave forecast if the coupled current-wave model was used.

\subsection{Modified wind drag}

The differences between the reference run and the simulation using the wave-modified wind drag depend on the field of interest. The surface elevation field adjusts faster to the wind stress than the density field. Thus, the discrepancies between the two simulations in terms of surface elevation have the same time and space scales than the wind field. On the other hand, the density field needs more time to adjust to the wind and it correspondly shows a larger memory. The differences in that field are less variable in time and space but they last for a longer period. Finally, the velocity field is an intermediate case. Discrepancies in the low frequency band, associated to quasi-geostrophic dynamics, behave as the density field, while in the high frequency band, (i.e. associated to the inertial oscillations), the differences directly depend on the wind stress input, so they behave as the surface elevation field.

During the storm, the run with the modified wind drag presents big differences in the surface elevation field, specially near the coast, where the upwelling is stronger than in the reference run (see Fig. 5). The slope front meandering is also changed, as shown by the density field (see Fig. 6). The amplitude of the front oscillations is reduced due to the enhanced mixing in the Ekman layer ( until $50 \mathrm{~m})$. Also, the eddy in the central part of the domain has a different shape and the horizontal density gradients are reduced.

The velocities in the surface layer have a similar structure. However some spatial shift has been detected in the main
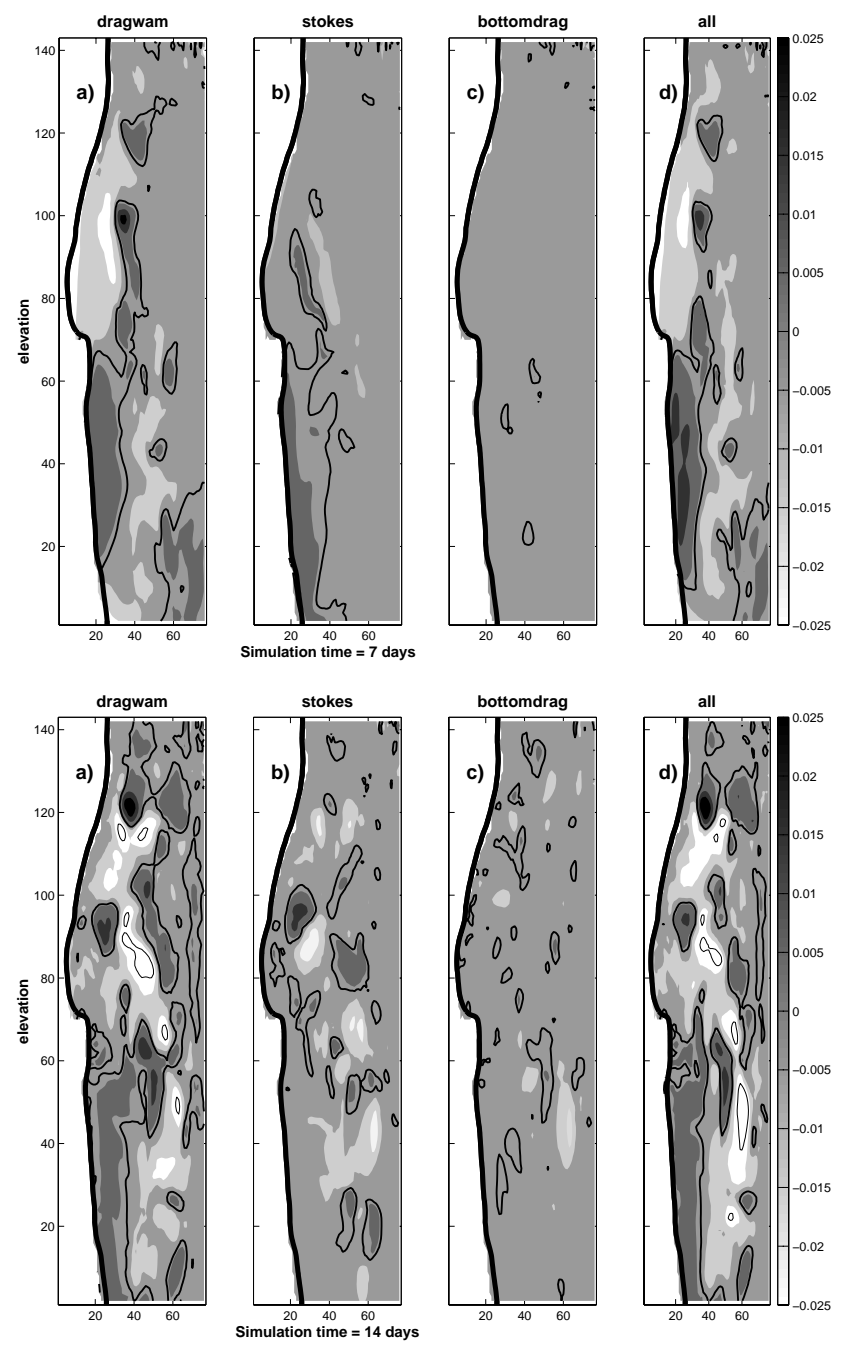

Fig. 5. Comparison of the effects of the waves over the circulation model surface elevation. It is represented the differences in the field using the (a) wave-modified wind drag, (b) considering the Stokes drift, (c) using the wave-modified bottom drag and (d) considering the whole wave-current coupling. In the top row there are the results during the storm (day 7.5) and in the bottom row the results at the end of the simulation period (day 14). The thick line shows the zero difference.

structures (front meandering, eddy), which is in good agreement with what has been commented above (see Fig. 7).

Looking at different depths, it is found that most of the discrepancies are located within the Ekman layer $(\sim 50 \mathrm{~m})$ except over the wide shelf area in the south of the domain. There, the circulation is mainly driven by the wind stress originating 3-D patterns that affect the whole water column. Thus, differences in the wind stress produce changes in the 3-D structure of the wide shelf hydrodynamics when winds are significative.

At the end of the simulation period, which corresponds to a calm period, the dynamics are mainly driven by density 

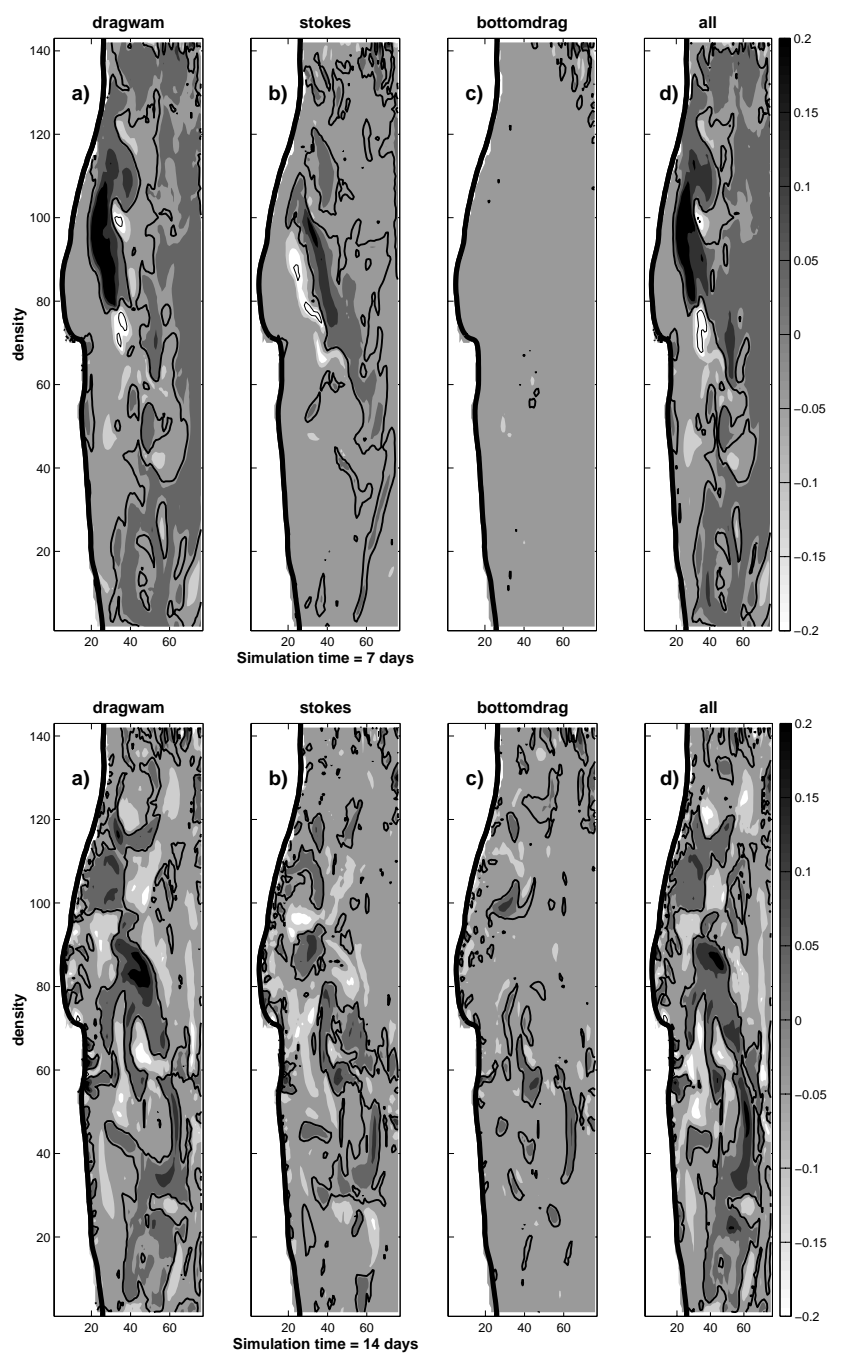

Fig. 6. The same than Fig. 5 but for the density field. The thick line shows the zero difference.

gradients. The density field is quite similar to the reference run except for the differences induced during the storm period. The same structures are present (slope front meandering, eddies) with similar shape and strength, but there are some shifts in their positions. On the other hand, the circulation over the wide shelf is very similar to the reference run and the, initially different, secondary current associated to the upwelling has disappeared.

To set a more complete view of the new wind drag effects, the temporal evolution of the rmse can be looked at (see Fig. 8a). We compute it first using all the data in the upper $20 \mathrm{~m}$ of the water column in order to describe the effects in the shallower levels. Afterwards, we compute it using only data over the inner shelf (bottom depth $<50 \mathrm{~m}$ ) in order to describe the effects in the more coastal domains. To have an idea of the relative importance of this rmse we also plot the standard deviation of the corresponding field.
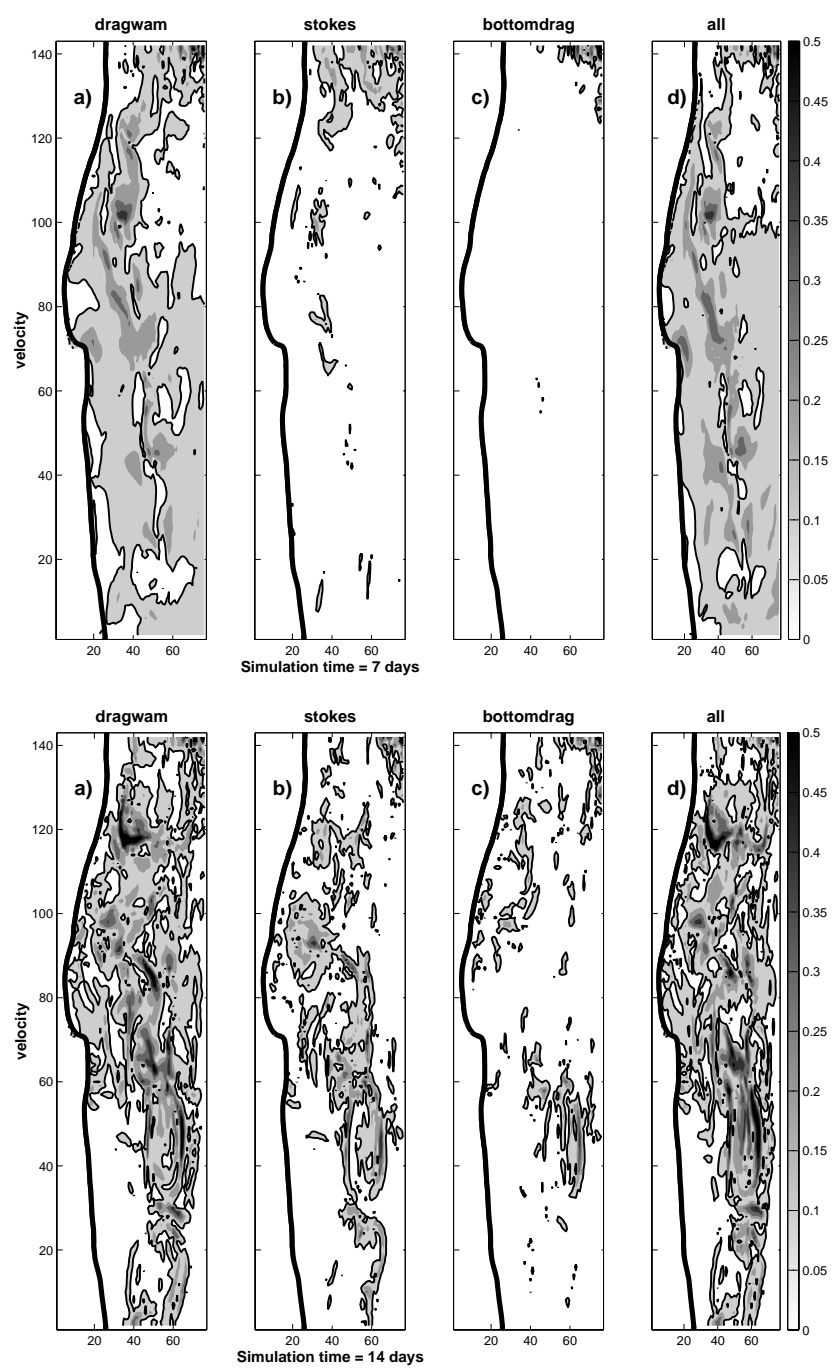

Fig. 7. The same than Fig. 5 but for the velocity field. The contours interval is $10 \mathrm{~cm} / \mathrm{s} \mathrm{kg} / \mathrm{m}^{3}$. The thick line shows the $10 \mathrm{~cm} / \mathrm{s}$ difference.

Looking at the elevation field in all the domain, the rmse reaches a quasi-stationary level of $1 \mathrm{~cm}$ after one day. This value is three times smaller than the field variability $(\sim 3 \mathrm{~cm})$. In contrast, if we focus on the inner shelf (see Fig. 8b) we find a more variable behaviour. The rmse is comparable to the field variability and both are non-stationary. This is due to the fact that the elevation in the inner shelf is very influenced by the upwelling-downwelling processes. Differences in the wind stress caused by different drag coefficients or by different wind strengths have an important impact on the elevation near the coast. In the open sea these differences have a minor impact, so the rmse computed over all the domain is lower and more stationary.

A similar behaviour is found looking at the density field (see Fig. 9). Considering the whole domain, we find that the rmse is four times smaller than the field variability. After a 

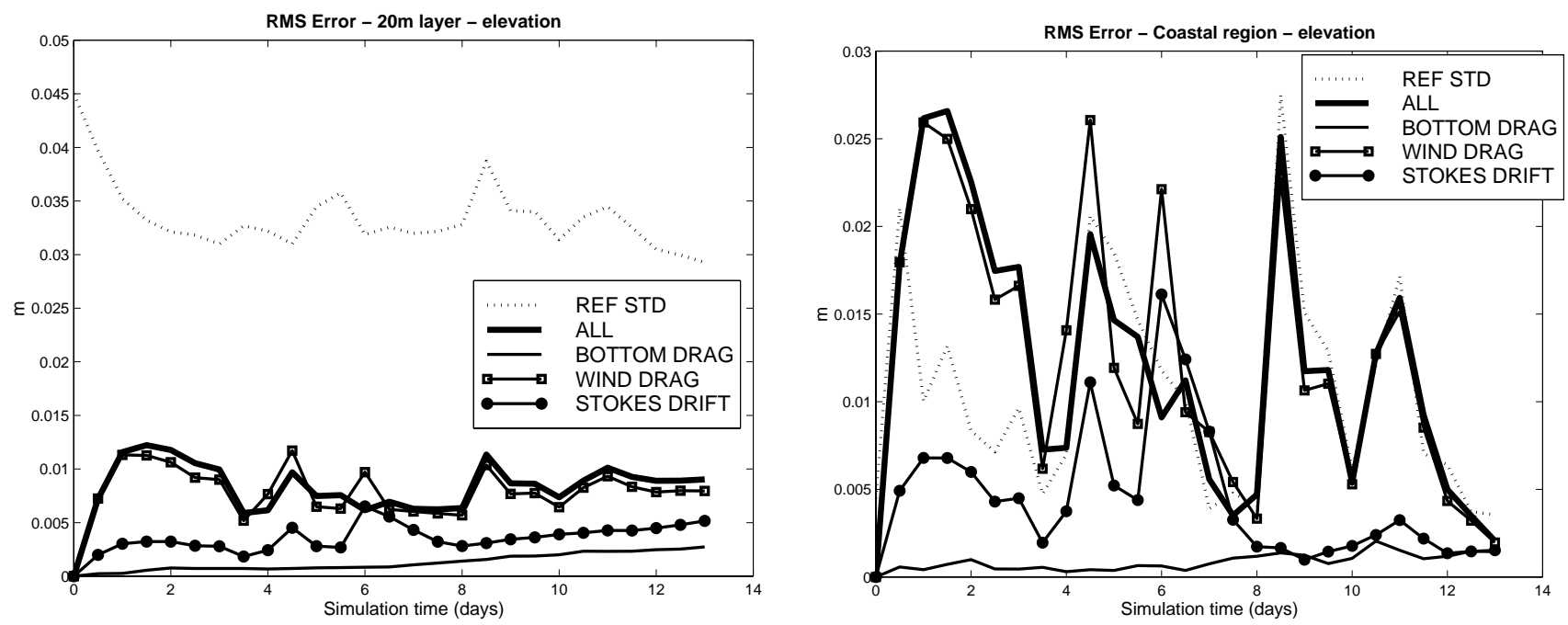

Fig. 8. Time evolution of the surface elevation rms error for the different runs. (a) Considering the first $20 \mathrm{~m}$ of the water column. (b) Considering the points in the inner shelf (bottom depth $<50 \mathrm{~m}$ ).

two days spin up period, the values remains stable. On the other hand, if we look at the coastal region, the difference in density due to the new wind stress are comparable to the field variability. This is again due to the sensitivity of this region to the wind field. In contrast to what happens with the elevation field, the density field has more inertia so its changes are much smoother.

Finally, the rmse in the velocity field reflects the same processes mentioned before. The high frequency component is more variable with time and more dependent on the instant wind, as for the elevation field. However, the low frequency part, in quasi-geostrophic equilbrium, is more dependent on the density field. Thus, the differences in this part are smoother but always increasing.

\subsection{Wave induced mass flux}

The spatial and temporal structure of the wave induced mass flux (the Stokes drift) is very similar to the wave height field, as suggested by the formulation in Eq. (5). In our simulations, the Stokes drift at the free surface had mean values of $15 \mathrm{~cm} / \mathrm{s}$ during the storm event and $3 \mathrm{~cm} / \mathrm{s}$ during the calm period. Its influence in the vertical vanishes at $10-15 \mathrm{~m}$ depth depending on the wave height regime.

The effects over the different fields during the storm (see Figs. 5-7) are smaller than in the previous case. Maximum differences are found over the wide shelf and near the shelf break in the center part of the domain. Over the wide shelf, where the underlying circulation was weak, those differences are produced by high wave height values during the storm. In such places, the Stokes drift becomes the main, although weak, forcing. On the other hand, near the shelf-break there was the density front and the slope current associated to it. The instant effects of the Stokes drift are less important, as far as the slope current velocities are much greater. Nevertheless, a coherent and constant forcing during a couple of days can slightly modify the position of the slope front. In consequence, as the horizontal density gradients are quite important, the differences in the density field are very visible (see Fig. 6).

After the storm, when the wind is calm, the density gradients become the main forcing. The differences between the run with the wave induced mass flux and the reference run, are due to the modifications of the density field induced during the storm. The shape of the main structures are slightly modified, and small differences in the field can lead to significative differences in their gradients. Also the spatial shift of the structures can produce high differences locally although they are of a transient nature (see Fig. 7).

The time evolution of the rmse (see Figs. 8-9) clearly shows the initial period where the wave field is weak. The rmse for all variables starts to increase in the fourth day, when the wave height does so. The values are smaller than the rmse induced by the modified wind drag but there are also significative increasing during all the simulation period. The rmse values computed in the whole domain, show that the elevation field, which adjusts faster to the transients, present two local maxima associated to the storm. The density field rmse is smoother while the velocity shows a mixed type of behaviour, as commented in the previous section. There is the part corresponding to the low frequencies which evolves smoothly and the part associated to the transients which changes faster.

When the rmse parameter is computed in the inner shelf, the values are greater reaching the levels of the field variability. It is interesting to compare with the rmse induced by the modified wind drag in the coastal region. The levels on the density field needs more time to spin up but after 15 days of 


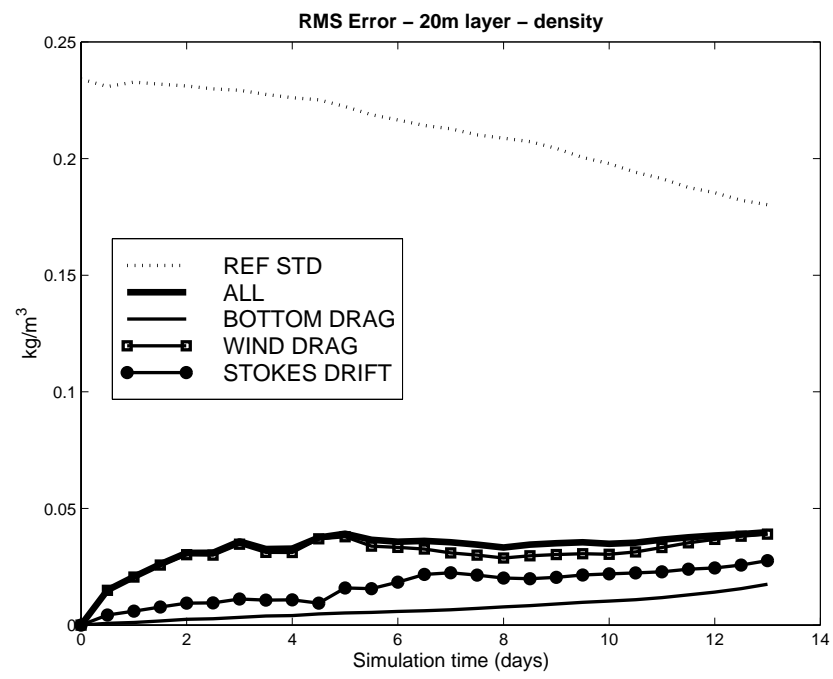

Fig. 9. As Fig. 8 but for the density field.

simulation they become similar. On the other hand, for the elevation and the velocity the maximum levels are the same but the time evolution is different.

\subsection{Modified bottom friction}

We have been using the Grant and Madsen (1979) formulation for the bottom drag coefficient which imposes a variable value depending on depth and wave conditions. In our simulation, the values ranged from $2 \cdot 10^{-3}$ in deep areas or calm periods to 0.1 in the inner shelf during the storm. This is a wide range of values but the main variability is found in regions where the bathymetry is shallower than $10-20 \mathrm{~m}$. For greater depths the wave influence was not noticeable.

In our domain, there is a small fraction of area where the bathymetry is shallower than $20 \mathrm{~m}$. In consequence, the run with the modified bottom friction doesn't differ too much from the reference run.

The differences in the elevation field are located in the coastal domain and they are very small, even in the storm period (see Fig. 5). The same happens to the density field (see Fig. 6), where the differences are not significative at all. Finally, the effect over the velocity field is just noticeable near the bottom in the southern wide shelf. These differences can be of $5-10 \mathrm{~cm} / \mathrm{s}$ but it must be noted that they do not have a strong influence in surface velocities (see Fig. 7)

Looking at the time evolution of the rmse (see Fig. 8) the same conclusion can be reached. The rmse values are always much smaller than the values induced by the Stokes drift or the modification of the wind drag during all the simulation period. However, an interesting point is that those values increase monotonically and smoothly with time. The time variability of the forcings (wind and waves) is not reproduced by this parameter.

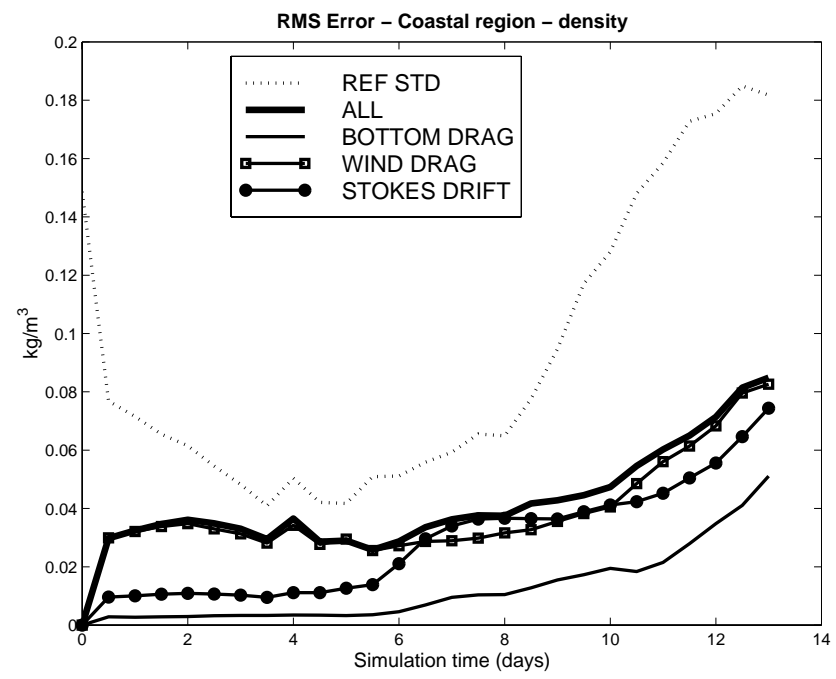

The role of the new bottom drag coefficient can be understood as a new forcing applied over the reference run. This force is weak but localized in the shallower regions and acts as a constant forcing. The effects of this new forcing, although negligible in the short term, could accumulate reaching significative values after a long period. Nevertheless, in the operational framework, the runs never last so long.

\subsection{Complete wave-current coupling}

The effects of the complete wave-current coupling are just a combination of the effects shown above. Basically, and since the wind drag modification is the most important effect, the behaviour with the complete coupling is similar to what has been shown in Sect. 4.3.

In the storm period, the run with complete coupling shows strong differences in the upwelling region in terms of surface elevation and density. The circulation over the shelf, which is wind dominated, presents also some discrepancies. Finally, the slope front meandering is significatively modified while the inertial oscillations are shifted in space and time.

At the end of the simulation the conclusion is the same, showing that differences are mainly induced by the modified wind drag coefficient. The main comments are redundant with what was already explained in Sect. 4.3.

In any case, it seems interesting to look at the rmse time evolution in order to have a more comprehensive view of the situation (see Figs. 8 and 9). The question is whether the different effects accumulate the errors or if they may compensate. What the figure suggests is that almost all the time and with all the different variables, the rmse of the full coupled run is greater than for the other simulations. As it was expected, the addition of the different elements generates more differences. It seems that the main contribution to that rmse is the modification of the wind drag. However, what is 

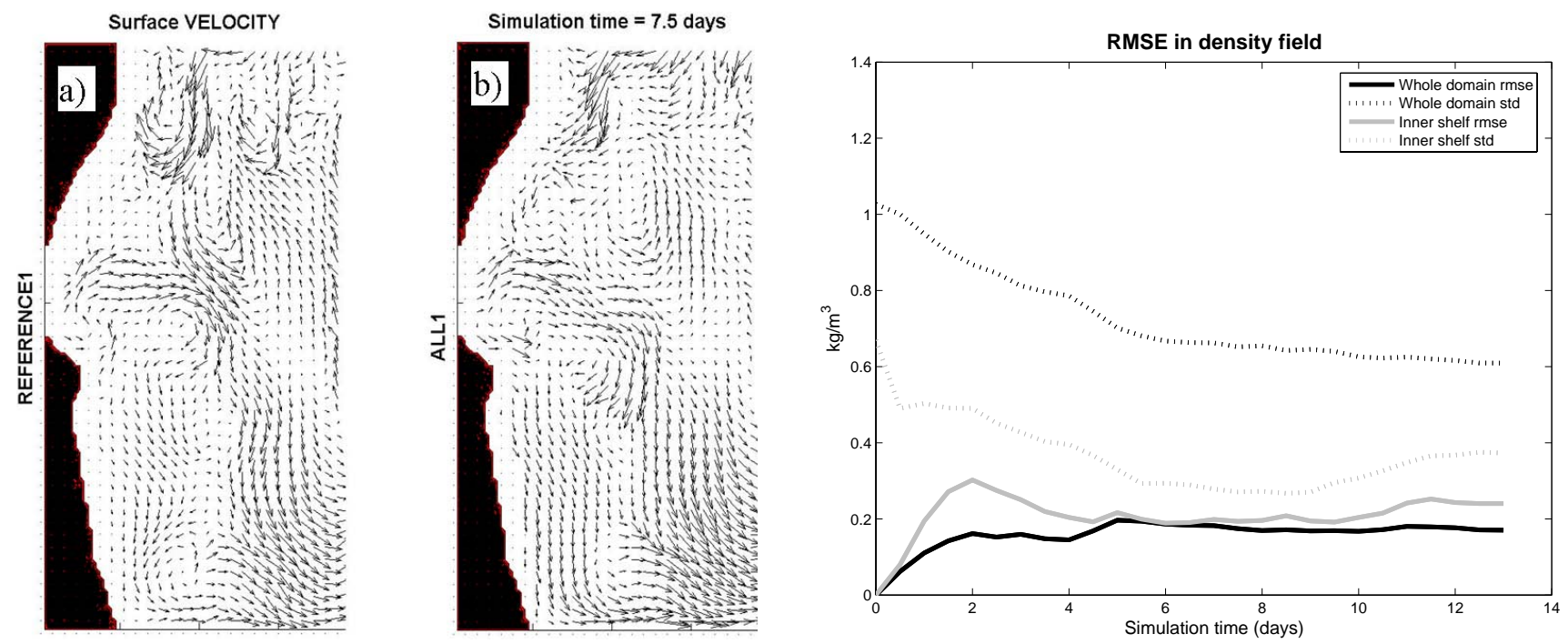

Fig. 10. Comparison of the reference run and the coupled wave-current run when stratification is considered. (a) Surface velocity at the end of the simulation for the reference and (b) the coupled run. (c) Time evolution of the density rms error between both simulations.

interesting to notice is that the values are not equal to a simple addition of the different rmse. In other words, we can not simply add the different contributions to figure out what the full (three-term) coupled system would produce.

\subsection{Impact of stratification}

All the results presented above have been obtained during the winter period where the water column is highly homogenized. However, the waves effects over the currents are mainly concentrated in the upper layers and how these effects are transmitted to the water column can depend on the vertical stratification. Thus, we explore the role of stratification in the current-wave coupling by repeating the same experiment of Sect. 4.6 but using a summer density profile.

First of all, the evolution of the reference run is different. The stratification prevents the formation of the current meandering and favors the formation of an anticyclonic eddy in the north. The slope current loses its signal in the upper layers where it is disrupted by the wind-induced circulation. In deeper layers, the slope current shifts its position towards the shelf break. The patterns of the wind-induced circulation are similar to the case with a winter density profile. The exception is the anticyclonic eddy generated by the NW winds which is intensified, as explained in Jordà (2005). Finally, the upwelling processes lead to greater horizontal gradients, and the vertical mixing is more inhibited.

The stratification also reduces the vertical dissipation of the energy introduced by the wind. The wind stress effects over the shallower layers is greater than in the case with a homogeneous density profile. In consequence, the divergence between the coupled model and the reference run will be more significative when looking at wind-induced processes, and in particular, those linked to the use of a different wind drag coefficient. The role of the wave induced mass flux seems to be the same.

Near the coast, the signal of upwelling processes changes as well as the modification of mesoscale features over the shelf (see Fig. 10). The mixing in the Ekman layer is more noticeable because vertical gradients are enhanced. Now, the differences between the reference and the coupled run are restricted to the first $20-30 \mathrm{~m}$ while in the homogeneous case they can extend to $50 \mathrm{~m}$.

If we look at the rmse in the density field (see Fig. 10), it can be seen how the values are now much greater than in the homogenous case (see Fig. 8). This is normal as far as the density gradients are also greater. What is interesting is that the field variance is also increased and the ratio between field variance and rmse is maintained in both cases.

\section{Discussion}

The sensitivity experiments carried out have shown the relative importance of the main coupling mechanisms between waves and currents, and how those mechanisms could affect the accuracy of the forecasts in the Mediterranean shelf-slope regions.

The wave refraction produced by surface currents seems to be of second order of importance, at least at basin scale. Unlike the results found by other authors in regions dominated by tides (e.g. The North Sea; Osuna and Monbaliu, 2004), wave refraction in a microtidal context such as the NW Mediterranean is small. Surface currents rarely exceed $1 \mathrm{~m} / \mathrm{s}$ and the ratio between the currents magnitude and the wave phase celerity is normally lower than 0.1 . Nevertheless, 
Table 3. Different drag coefficients obtained from several published formulations.

\begin{tabular}{lccc}
\hline Wind velocity & \multicolumn{3}{c}{ Wind drag coefficient formulation } \\
\hline & Heaps (1965) & Wu (1982) & $\begin{array}{c}\text { Janssen (1991) } \\
\text { (also depends on } \\
\text { the wave state) }\end{array}$ \\
\hline $5 \mathrm{~m} / \mathrm{s}$ & $0.510^{-3}$ & $1.1210^{-3}$ & $1.1010^{-3}$ \\
$15 \mathrm{~m} / \mathrm{s}$ & $1.8310^{-3}$ & $1.7710^{-3}$ & $1.9210^{-3}$ \\
\hline
\end{tabular}

it is interesting to notice that wave refraction is a process acting in the whole domain and which can be perceived wherever the currents are relevant. In other words, it could be seen as a "local effect". Also, the operational wave forecasting do not presently have the required spatial resolution for coastal regions and the obtained results may not be applicable to very local areas near the coast with strong currents (i.e. linked to a river outflow). In that case more specific experiments should be done with the appropiate numerical models.

The modification of the wind drag coefficient by wave effects has a strong impact over the current forecasts. In shelf regions such as the Catalan southern shelf, where the wind is the main forcing, slight modifications of the wind stress can lead to significant modifications of the current and density fields. The sensitivity experiments have shown that the location and spatio-temporal scale of those differences depend on the wind field structure and scales. However, when the thermohaline structure is modified due to mixing or upwelling processes, the effects of the new wind stress can last longer. Thus, it seems evident that it is important to carefully choose the parametrization for the wind drag coefficient. The problem is that there exists significative discrepancies among the different formulations present in the literature (see Table 3), so that the best choice is not always easy.

Another element of the coupling is the bottom friction modification by wave effects. Its impact over the currents is mainly local and it is more noticeable where the bottom depth is reduced (i.e. inner shelf and near-shore). It also requires enough spatial extent to be significative. As it has been commented in Sect. 4.4 the modifications of the bottom friction by the effect of waves is limited to very shallow areas. On the other hand, typical shelf models cover a domain extending from the coast to the slope region. In consequence, the fraction of the domain where the bottom drag modifications by waves can be noticeable is usually small. Thus, the overall effect on shelf and regional models would not be important. In very coastal domains, however, more tests should be done to evaluate its quantitative importance. Also, in areas with typical wave periods longer than in our case the fraction of shelf significatively affected by bottom friction would be increased. As an example, a simple computation of bottom drag coefficient using Grant and Madsen (1979) formulation
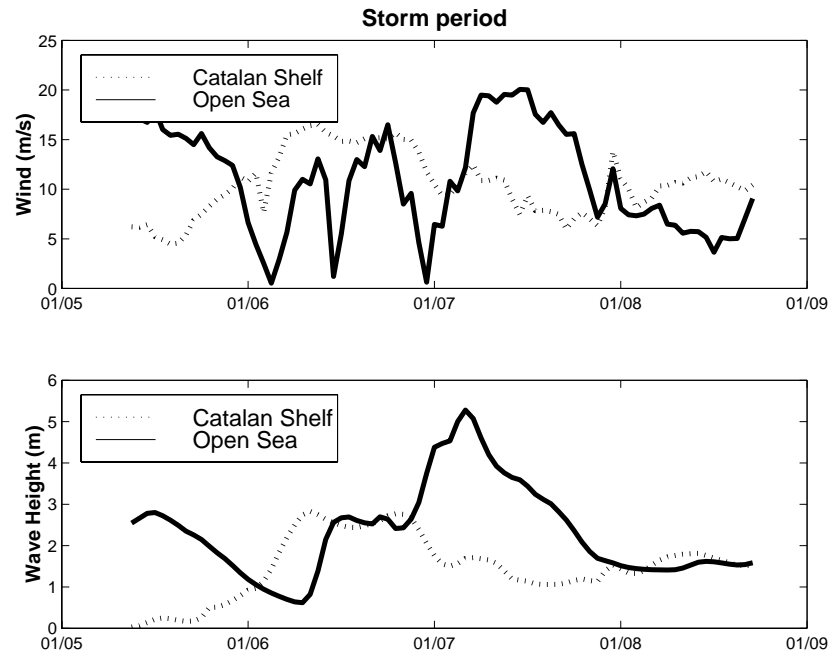

Fig. 11. Wind (top) and wave height (bottom) time series during the storm period for a location in the Catalan Shelf (dotted line) and in the open sea (solid line). See Fig. 1 for location of points.

can be done. In storm conditions ( $\mathrm{Hs}=3 \mathrm{~m})$, waves with period of $5 \mathrm{~s}$ (typical in the region) generate a bottom drag coeficient of $\mathrm{C}_{D}=0.113$ at $5 \mathrm{~m}$ depth. If period was longer ( $12 \mathrm{~s}$ ), the same drag coefficient would be obtained for $12 \mathrm{~m}$ depth.

Finally, the inclusion of the Stokes drift has shown to be significant. The magnitude of the drift is small when compared to current velocities but it has some characteristics that increase its importance. The Stokes drift effects are cumulative and after some time their impact can become more relevant. The time and spatial scales coincide with the wave field scales which are usually larger than the wind scales. This is specially important in shelf areas where the winds are more restricted by the land topography. It is also important to notice that the wind and wave fields do not necessarily coincide (see Fig. 11) and that the wave field can be dominated by the waves generated in remote regions. So, in sheltered shelf regions or in calm (swell dominated) periods, the Stokes drift can become an important forcing mechanism.

Another way to look at the impact of waves over the currents is focusing on the modifications induced in the different fields. If we look at the high frequency component of the shelf-scale hydrodynamics we find that it is mainly influenced by the wind field. The surface elevation and the high frequency part of the velocity field strongly depend on the wind stress. Thus, a bad representation of the wind drag coefficient can alter those fields. On the other hand, they have a short "memory", so that in calm periods or in regions where the winds are not so important, the differences reduce. The low frequency component of the system is represented by the velocity field in quasi-geostrophic equilibrium and driven by the density field. In that case those fields have more inertia and, consequently, "more memory". They are more difficult to modify but they accumulate the small perturbations, so 

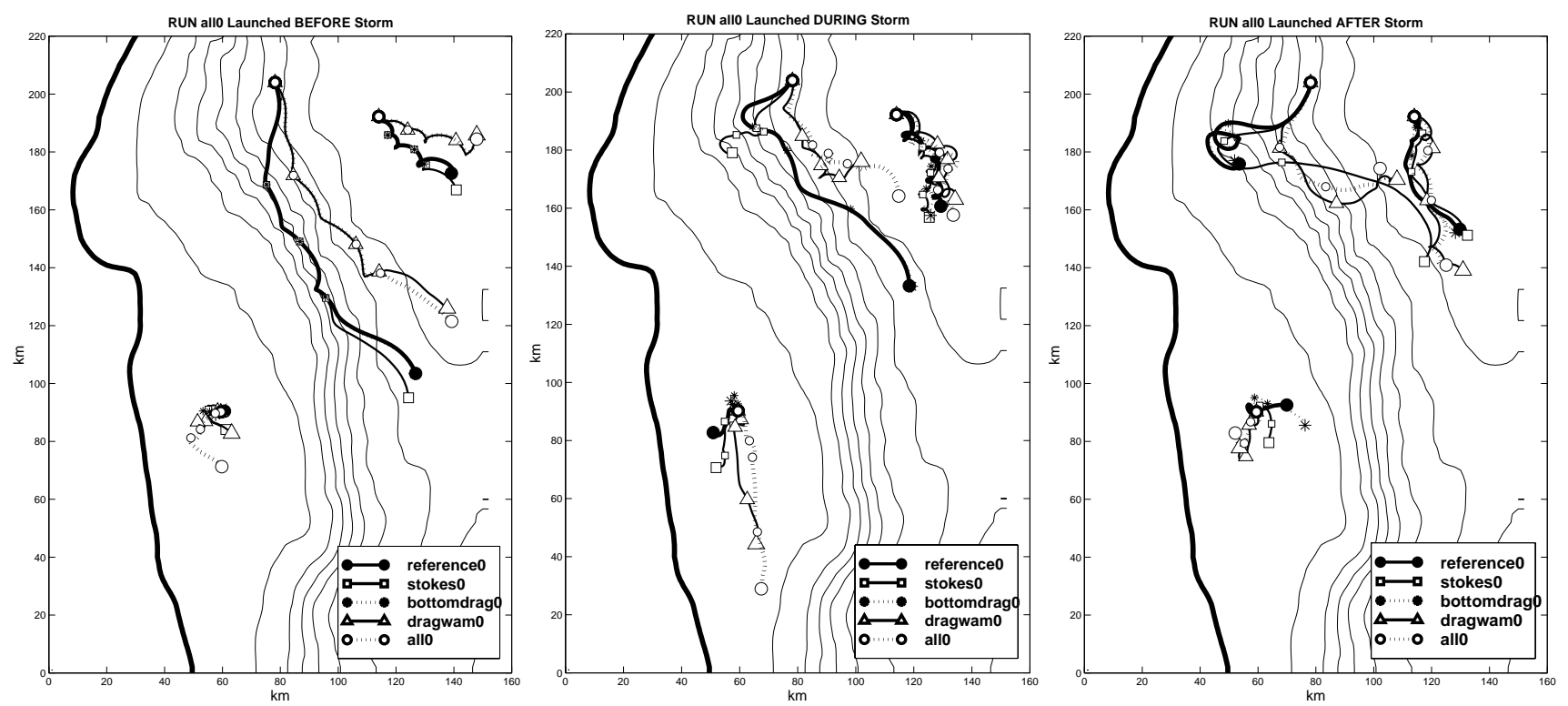

Fig. 12. Simulated lagrangian buoys launched in different moments: (a) before the storm, (b) during the storm and (c) after the storm.

they can last even after the forcings (wave, wind) stop. In those conditions, the modified wind stress could have an impact if the wind blows long enough to modify (by mixing or boundary effects) the density field. The Stokes drift, being less intense, is more persistent, so it can modify the density field and the low frequency component of the velocity field.

For completeness, in Sect. 4.7 the impact of seasonality has also been explored. It is obvious that, as far as the physical processes are different, the impact of waves over the current will also be different. That is in effect what happens. However, it seems that the relative importance of each factor is maintained. Also, the error that could be introduced by not considering the coupling has a similar relative importance with or without stratification.

Another interesting diagnostic that can be done is to compute lagrangian trajectories for the different simulated scenarios. One of the main applications of the current forecasts is the control of oil spill emergencies or the tracking of floating objects. So, it seems appropiate to compute the different trajectories that would be predicted by the model if the different coupling elements were included. Also, the lagrangian trajectories computed for several days are an integrating measure of the current "errors".

We have simulated several drifting buoys launched in three different locations: over the shelf, over the slope and in the open sea (see Fig. 12). The trajectories last for four days and the launching was done in three different moments: before, during and after the storm.

The trajectories described by the buoys clearly depend on the launching point. Over the shelf, the velocities were small except during the storm when strong winds blow. In consequence, the distance travelled by the buoys was also reduced except during that period. Over the slope, the main forcing is the permanent slope current which advects the buoys for greater distances in all periods. In addition to that, the wind induced circulation is overimposed to that pattern. This significatively affects the buoy trajectories during the storm, when they are forced to leave the slope region. Finally, in the open sea, the trajectories are partially affected by the slope current and by the wind. The distance travelled by those buoys is almost the same in all periods.

Before the storm, all runs lead to similar trajectories (see Fig. 12a). The factor "disturbing" more the buoys path is the modified wind drag coefficient which induces a slight change of the main direction. Also, it is clear that the whole coupling is dominated by that factor. Nevertheless, it is interesting to notice that over the shelf, the contribution of the Stokes drift and the modified wind drag coefficient are comparable.

During the storm, the wind and wave effects are enhanced and the different trajectories are further apart. In the open sea, all buoys are dominated by inertial oscillations and their final positions are similar without a clear element dominating the coupling. Over the shelf, the different coupling mechanisms have a similar effect although the displacements are obviously enhanced by the effects of the winds and waves. Finally, over the slope, an interesting behaviour can be found. The effects of the modified wind stress make the buoys to go to the open sea, where the slope current is weaker. Thus the main driving mechanism is reduced and the trajectories move away from the reference buoy. On the other hand, the Stokes drift also acts pushing the buoy in the opposite direction, over the shelf. There, no slope current is found and the only forcings are the wind and the Stokes drift. In that case, the total displacement is much smaller than for the reference buoy. 
This behaviour leads us to think of the shelf-slope region as a bimodal system with two equilibrium positions (attractors), one over the shelf and the other over the slope. Small perturbations around those positions lead to small changes in the final position except when the buoy is pushed towards a different attractor. Then, the final positions can greatly differ. What has been shown here is that the Stokes drift is enough to change the equilibrium state of the buoy.

After the storm, the description is quite similar. In the open sea and over the shelf there is a dispersion of the different buoys, and all the coupling mechanisms act in a similar way. Over the slope, however, there appears again the bi-modal behaviour. The enhanced wind stress and the Stokes drift force the buoys to leave the shelf and to come into the slope current path. Thus, the final positions are again far away from the reference situation.

Finally, it is worthwhile to highlight the role of the enhanced bottom friction. Over the slope and in the open sea no difference with respect to the reference run is found. However, over the shelf, its effects are much more visible. As it was commented in previous sections, the enhanced bottom friction is noticeable when the bottom depth is reduced $(z<40-50 \mathrm{~m})$. Although its effects are smaller than the modified wind drag or the Stokes drift, they are still far from negligible.

The relative importance of the different terms analysed in this paper is obviously dependent on the study region. In other regions with different wind, waves and currents climate the results would probably differ. In areas affected by larger wave storms, the Stokes drift as well as the enhancement of bottom friction would have a greater impact. This last parameter would also be affected where the typical wavelength is larger as shown above. Finally, in all cases, the uncertainties about the modification of the wind drag by waves would have a significant role. On the other hand, in regions where the wave climate is mild or where the currents are strong enough to completely control the dynamics the wave effects over currents would be negligible. For what is concerned to the Western Mediterranean, the characteristics in terms of wind strength, microtidal environment and currents and wave climate are not very different from the Catalan region where this study is focused. In consequence, we expect this results to be qualitatively extrapolable to other shelf regions of the Western Mediterranean. In any case, we recommend to do a scaling analysis, as it has been done above, to have an idea about the relevance of the different coupling mechanisms in each region.

In an operational framework, a fully coupled wave-current system covering all spatial scales from basin to coastal domains is not yet feasible. An alternative could be a sequential approach like the one presented here. In that case some remarks are necessary. The impact of currents over the waves at basin scale has shown to be negligible and not including it is not a major shortcoming for the predictions. Nevertheless, at very local scales (nearshore), the situation changes
(Sánchez-Arcilla and Lemos, 1990) and a coupled system would be preferred. On the other side, we have shown how the waves have a significant impact over the currents. However, it is possible that not all circulation models at different scales are able to consider that coupling. In that case we would find that the different nested models would include different physics. When the initialization procedure is carried out (usually every week), the physics developed by the high resolution (HR) model (including wave effects) would be removed by the initial field from the coarser model (LR; without wave coupling). On the other hand we have that the high frequency processes (i.e. induced by wind) could be reproduced by the HR model in the spin up phase (1-3 days), but that other, more accumulative, processes would not. In consequence we would recommend that the initial field used in the restarting was a combination between the HR and the LR fields using some kind of frequency dependent nudging.

\section{Conclusions}

In this paper we have explored the influence of the currentwave coupling on the hydrodynamic forecasting. The approach has been to use a sequential one way coupling which has some conceptual limitations but which is more practical in present operational configurations. We have run several sensitivity tests to assess which elements of the coupling system are more relevant. At basin scale, the currents seem to have no great influence over the wave forecasts. On the other hand, the wave impact over the currents is much more significative. The modification of the wind drag coefficient by waves appeared to be the most crucial element, specially in regions where the wind induced dynamics have a predominant role. The Stokes drift is a weaker forcing but in regions where the wind is weak it gains relevance. Finally, the enhanced bottom friction is just significative in coastal domains. For shelf domains its importance is secondary but if more coastal or nearshore domains are modelled it would be worth to include it. These conclusions, derived for a microtidal semi-enclosed sea such as the NW Mediterranean are expected to be applicable to other similar environments where the relative balance of drivers and constraints lead to similar hydrodynamical patterns.

Acknowledgements. The authors would like to thank P. Marsaleix for his help in the model coupling set up. The authors would like to thank SMC (Meteorological Service of Catalonia) for their support and help with the atmospheric and marine data. This work has been done in the framework of the MFSTEP (EU Contract Number EVK3-CT-2002-00075)

Edited by: N. Pinardi 


\section{References}

Ardhuin, F. and Jenkins, A. D.: On the interaction of surface waves and the upper ocean turbulence, J. Phys. Oceanogr., 36, 551-557, 2006.

Auclair, F., Marsaleix, P., and Estournel, C.: The penetration of the northern current over the Gulf of Lion (western Mediterranean Sea) as a downscaling problem, Oceanol. Acta, 24, 529-544, doi:10.1016/S0399-1784(01)01166-5, 2001.

Baumert H., Chapalain, G., Smaoui, H., McManus, J. P., Yagi, H., Regener, M., Sundermann, J., and Szilagy, B.: Modelling and numerical simulation of turbulence, waves and suspended sediments for pre-operational use in coastal seas, Coast. Eng., 41 63-93, 2000.

Bolaños, R., Sánchez-Arcilla, A., Gomez, J., and Cateura, J.: Limits of Operational Wave Predictions in the North-Western Mediterranean, Proceeding of the ICCE, 3, 818-829, 2004.

Bolaños, R., Sánchez-Arcilla, A., and Cateura, J.: Evaluation of two atmospheric models for wind-wave modelling in the NW Mediterranean, J. Marine Syst., 65, 336-353, 2007.

Brozková R., Derková, M., Belluš, M., and Farda, A.: Atmospheric forcing by ALADIN/MFSTEP and MFSTEP oriented tunings, Ocean Sci., 2, 113-121, 2006, http://www.ocean-sci.net/2/113/2006/.

Craig, P. D. and Banner, M. L.: Modeling wave-enhanced turbulence in the ocean surface layer, J. Phys. Oceanogr., 24, 25462559, 1994.

Davies, A. M. and Lawrence, J.: Examining the Influence of Wind and Wave turbulence on tidal currents, using a three-dimensional hydrodynmic model including wave-current interaction, J. Phys. Oceanogr., 24, 2441-2460, 1994.

Dufau-Julliand, C., Marsaleix, P., Petrenko, A., and Dekeyser, I.: Three-dimensional modeling of the Gulf of Lion's hydrodynamics (northwest Mediterranean) during Jannuary 1999 (MOOGLI3 Experiment) and late winter 1999: Western Mediterranean Intermediate Water's (WIW's) formation and its cascading over the shelf break, J. Geophys. Res., 109, C11002, doi:10.1029/2003JC002019, 2004.

Estournel, C., Durrieu de Madron, X., Marsaleix, P., Auclair, F., Julliand, C., and Vehil, R.: Observation and modelisation of the winter coastal oceanic circulation in the Gulf of Lions under wind conditions influenced by the continental orography (FETCH experiment), J. Geophys. Res., 108(C3), 7-1-7-18, doi:10.1029/2001JC000825, 2003.

Estournel, C., Zervakis, V., Marsaleix, P., Papadopoulos, A., Auclair, F., Perivoliotis, L., and Tragou, E.: Dense water formation and cascading in the Gulf of Thermaikos (North Aegean) from observations and modelling, Cont. Shelf Res., 25, 2366-2386 doi:10.1016/j.csr.2005.08.014, 2005.

Font, J., García-Ladona, E., and Górriz, E. G.: The seasonality of mesoscale motion in the Northern Current of the Western Mediterranean: several years of evidence, Oceanol. Acta, 18(2), 207-219, 1995.

Garcia, M., Sanchez-Arcilla, A., Sierra, J., Sospedra, J., and Gomez, J.: Wind Waves Off The Ebro Delta, Nw Mediterranean, J. Marine Syst., 4(2-3), 235-262, 1993.

Geernaer, G. L.: Bulk parametrizations for the wind stress and heat fluxes, in: Surface Waves and Fluxes, Current Theory, vol. 1, 36 pp., Kluwer Acad., Norwell, Mass., 1990.

Gill, A. E.: Atmosphere-Ocean Dynamics, Academic Press, New
York, 662 pp, 1982.

Grant, W. D. and Madsen, O. S.: Combined wave and current interaction with a rough bottom, J. Geophys. Res., 84(C4), 17971808, 1979.

Haney, R. L.: On the pressure gradient force over steep topography in sigma coordinate models, J. Phys. Oceanogr., 21, 610-619, 1991.

Hasselmann, K.: Wave-driven inertial oscillations, Geophys. Fluid Dyn., 1, 463-502, 1970.

Heaps, N. S.: A Two-Dimensional Numerical Sea Model Philosophical Transactions of the Royal Society of London, Series A, Mathematical and Physical Sciences, 265(1160), 93-137, 1969.

Janssen, P. A. E. M.: Wave-induced stress and the drag of air flow over sea waves, J. Phys. Oceanogr., 19, 745-754, 1989.

Janssen, P. A. E. M.: Quasi-linear theory of wind generation applied to wave forecasting, J. Phys. Oceanogr., 21, 1631-1642, 1991.

Janssen, P. A. E. M., Saetra, O., Wettre, C., and Hersbach, H.: Impact of the sea state on the atmosphere and ocean, in: Proc. CD of the 2003 Waves and Operational Oceanography Workshop, edited by: Ardhuin, F., Service hydrographique et océanographique de la Marine, Brest, France, 2004.

Jenkins, A. D.: Wind and wave induced currents in a rotating sea with depth-varying eddy viscosity, J. Phys. Oceanogr., 17, 938951, 1987.

Jordà, G., Espino, M., and Marsaleix, P.: Implementation and validation of the south catalan shelf model, The Scientific Validation Period Experiment, MFSTEP Report, 2004.

Jordà, G.: Towards data assimilation in the Catalan Continental shelf, From data analysis to optimization methods, PhD Memory, Universitat Politècnica de Catalunya, 332 pp, 2005.

Kantha, L. H. and Clayson, C. A.: On the effect of surface gravity waves on mixing in the oceanic mixed layer, Ocean Model., 6, 101-124, 2004.

Komen, G. J., Cavaleri, L., Donelan, M., Hasselmann, K., Hasselmann, S., and Janssen, P. A. E. M.: Dynamics and Modelling of Ocean Waves, Cambridge University Press, 532 pp, 1994.

Mastenbroek, C., Burgers, G., and Janssen, P. A. E. M.: The dynamical coupling of a wave model and a storm surge model through the atmospheric boundary layer, J. Phys. Oceanogr., 23, 18561866, 1993.

McWilliams, J. C., Sullivan, P. P., and Moeng, C.-H.: Langmuir turbulence in the ocean, J. Fluid Mech., 334, 1-30, 1997.

Mellor, G. and Yamada, T.: Development of a turbuklence closure model for geophysical fluid problems, Rev. Geophys. Space Phys., 20, 851-875, 1982.

Mellor, G.: The three-dimensional current and surface wave equations, J. Phys. Oceanogr., 33, 1978-1989, 2003.

Mellor, G.: Some consequences of the three-dimensional current and surface wave equations, J. Phys. Oceanogr., 35, 2291-2298, 2005.

Melsom, A. and Saetra, O.: Effects of wave breaking on the nearsurface profiles of velocity and turbulent kinetic energy, J. Phys. Oceanogr., 34, 490-504, 2004.

Millot, C.: Circulation in the Western Mediterranean Sea, J. Mar. Syst., 20, 423-442, 1999.

Monbaliu, J., Padilla-Hernández, R., Hargreaves, J., Carretero, J. C., Weimin, L., Sclavo, M., and Gunther, H.: The spectral wave model, WAM adapted for aplications with high spatial resolution, Coast. Eng., 41, 41-62, 2000. 
Moon, I. J.: Impact of a coupled ocean wave-tide-circulation system on coastal modeling, Ocean Model., 8, 203-236, 2005.

Osuna, P. and Monbaliu, J.: Wave-current interaction in the Southern North Sea, J. Marine Syst., 52(1-4), 65-87, 2004.

Perrie, W., Tang, C. L., Hu, Y., and DeTracy, B. M.: The Impact of Waves on Surface Currents, J. Phys. Oceanogr., 33, 2126-2140, 2003.

Pinardi, N., Allen, I., Demirov, E., De Mey, P., Korres, G., Lascaratos, A., Le Traon, P.-Y., Maillard, C., Manzella, G., and Tziavos, C.: The Mediterranean ocean Forecasting System: first phase of implementation (1998-2001), Ann. Geophys., 21, 3-20, 2003 , http://www.ann-geophys.net/21/3/2003/.

Radnóti, G., Ajjaji, R., Bubnová, R., Caian, M., Cordoneanu, E., Von Der Emde, K., Gril, J.-D., Hoffman, J., Horányi, A., Issara, S., Ivanovici, V., Janoušek, M., Joly, A., LeMoigne, P., and Malardel, S.: The spectral limited area model ARPEGEALADIN, PWPR Report Series no. 7, WMO TD 699, pp 111118, 1995.

Rascle, N., Ardhuin, F., and Terray, E. A.: Drift and mixing under the ocean surface: a coherent one-dimensional description with application to unstratified conditions, J. Geophys. Res., 11, C03016, doi:10.1029/2005JC003004, 2006.
Salat, J., Garcia, M. A., Cruzado, A., Palanques, A., Arin, L., Gomis, D., Guillen, J., de Leon, A., Puigdefàbregas, J., Sospedra, J., and Velasquez, Z. R.: Seasonal changes of water masses structure and shelf slope exchanges at the Ebro Shelf (NW Mediterranean), Cont. Shelf Res., 22, 327-348, 2002.

Sánchez-Arcilla, A. and Lemos, C. M.: Surf-Zone Hydrodynamics, Centro Internacional de Métodos Numéricos en Ingeniería, Barcelona, 310 p., 1990.

Toba, Y., Smith, D., and Ebuchi, N.: Historical drag expressions, in: Wind Stress Over the Ocean, edited by: Jones, I. S. F. and Toba, Y., Cambridge University Press, pp. 35-53, 2001.

Vickers, D. and Mahrt, L.: Fetch limited drag coefficients, Boundary-Layer Meteorology, 85, 53-79, 1997.

Weber, J. E.: Attenuated wave-induced drift in a viscous rotating ocean, J. Fluid Mech., 137, 115-129, 1983.

Weber, J. E.: Wave-Induced Mass Transport in the Oceanic Surface Layer, J. Phys. Oceanogr., 33(12), 2527-2533, 2003.

Wu, J.: Wind-stress coefficients over sea surface from breeze to hurricane, J. Geophys. Res., 87(C12), 9704-9706, 1982.

$\mathrm{Xu}, \mathrm{Z}$. and Bowen, A. J.: Wave- and wind-driven flow in water of finite depth, J. Phys. Oceanogr., 24, 1850-1866, 1994. 